\title{
Direct Synthesis of Dimethyl Ether from Syn-gas over Cu-based Catalysts: Enhanced Selectivity in the Presence of $\mathrm{MgO}$
}

\author{
Sonal Asthana ${ }^{1,2}$, Chanchal Samanta ${ }^{1}$, Asim Bhaumik $^{3}$, Biplab Banerjee, ${ }^{3}$ Ravi Kumar \\ Voolapalli*1, Basudeb Saha*2,4 \\ ${ }^{1}$ Bharat Petroleum Corporation Ltd., Plot No: 2A, Udyog Kendra, Surajpur Industrial Area, Greater \\ Noida, Uttar Pradesh- 201306 \\ ${ }^{2}$ Laboratory of Catalysis, Department of Chemistry, University of Delhi, Delhi 110007, India. \\ ${ }^{3}$ Department of Material Science, Indian Association for Cultivation of Science, Kolkata 700032 , \\ India. \\ ${ }^{4}$ Catalysis Center for Energy Innovation, University of Delaware, Newark, DE 19713, USA.
}

Corresponding authors' Email:

bsaha@udel.edu (B Saha); ravikumarv@bharatpetroleum.in (R. Kumar).

\begin{abstract}
Direct synthesis of dimethyl ether (DME) from syn-gas was investigated over a series of hybrid catalytic systems containing $\mathrm{Cu}$-based methanol synthesis component with varying amount of $\mathrm{ZnO}$ and $\mathrm{MgO}$, and $\gamma-\mathrm{Al}_{2} \mathrm{O}_{3}$ as a methanol dehydration component. Methanol synthesis and methanol dehydration components were homogeneously mixed in 2:1 weight ratio to prepare the hybrid catalysts, which were characterized by Transmission electron microscopy, Scanning electron microscopy, BET surface area analyzer, Powder X-Ray diffraction, $\mathrm{NH}_{3}$-Temperature programmed desorption and $\mathrm{H}_{2}$-Temperature programmed reduction methods. Syn-gas to DME (STD) reaction was studied in an isothermal fixed bed reactor at 30 bar and $260{ }^{\circ} \mathrm{C}$. The catalysis results revealed an improved effectiveness of the catalyst in the presence of $20 \mathrm{~mol} \% \mathrm{MgO}$, enabling a significant enhancement in CO conversion from 19 to $37 \%$ and DME selectivity from 36 to 83\%, when compared with the activity of a catalyst without $\mathrm{MgO}$. By-products, $\mathrm{CO}_{2}$ and $\mathrm{C}_{1}-\mathrm{C}_{2}$ hydrocarbons, selectivity were also decreased from 48 to $14 \%$ for $\mathrm{CO}_{2}$ and from 8 to $2.5 \%$ for hydrocarbons. Catalyst performance, CO conversions and DME selectivity were evaluated by varying the reaction temperature, pressure, space velocity and $\mathrm{H}_{2} / \mathrm{CO}$ ratio in syn-gas. XRD data revealed the formation of a well crystalline malachite structure for the catalysts containing up to $20 \mathrm{~mol} \% \mathrm{MgO}$, but the crystallinity in the structure lost when $30 \% \mathrm{MgO}$ was added, resulting in a decreased catalytic activity.
\end{abstract}


Keywords: Dimethyl ether, $\mathrm{Cu} / \mathrm{ZnO} / \mathrm{MgO}$, hybrid catalysts, $\mathrm{MgO}$ effect, syngas, methanol dehydration, methanol synthesis.

\section{INTRODUCTION}

Dimethyl ether (DME) is gaining considerable attention worldwide as a cleaner fuel because of its environmentally benign fuel properties [1-2]. DME is a colorless gas (at STP) and can be liquefied at about 6 atm at $25{ }^{\circ} \mathrm{C}$, which allows its usage on the same platform of current LPG storage and distribution technologies with minor modifications [3]. The cetane number of DME (55-60) is higher than diesel oil ( 50). DME is also an excellent feedstock and intermediate for methyl acetate, dimethyl sulfate and light olefins [4].

Conventionally, DME is produced via a two-step process. The first step is the catalytic conversion of syn-gas to methanol and the second step is the dehydration of methanol over alumina or zeolite based acidic materials [5]. Methanol synthesis is a high temperature and high pressure process and is limited by thermodynamic constraints. Because of very low equilibrium of the conversion of syn-gas to methanol, direct conversion of syn-gas to DME (STD) has inherent thermodynamic advantage to achieve higher syn-gas conversion, and thus an overall economy of the process [6-8]. The key steps in the STD process are as follows:

$$
\begin{array}{lll}
2 \mathrm{CO}+4 \mathrm{H}_{2} \rightarrow 2 \mathrm{CH}_{3} \mathrm{OH} & \text { Methanol synthesis } & \Delta \mathrm{H}=-181.6 \mathrm{~kJ} / \mathrm{DME}-\mathrm{mol} \\
2 \mathrm{CH}_{3} \mathrm{OH} \rightarrow \mathrm{CH}_{3} \mathrm{OCH}_{3}+\mathrm{H}_{2} \mathrm{O} & \text { DME synthesis } & \Delta \mathrm{H}=-23.4 \mathrm{~kJ} / \mathrm{DME}-\mathrm{mol} \\
\mathrm{H}_{2} \mathrm{O}+\mathrm{CO} \rightarrow \mathrm{H}_{2}+\mathrm{CO}_{2} & \text { Water gas shift } & \Delta \mathrm{H}=-41.0 \mathrm{~kJ} / \mathrm{DME}-\mathrm{mol}
\end{array}
$$

Since direct conversion of syn-gas to DME also involves in situ methanol formation, the catalyst for the STD process must contain bifunctional sites for methanol synthesis and its subsequent dehydration. The most common hybrid catalysts containing bifunctional sites for direct conversion of syn-gas to DME are prepared either by physical mixing of both components or through co-precipitation of methanol synthesis catalyst and its subsequent impregnation on methanol dehydration catalyst [9-11]. In this process, DME selectivity strongly depends on the catalyst properties, such as acidity, nature of acid sites, pore size and crystallinity, and the reaction factors, such as temperature, pressure and space velocity of the feed stream. Under comparable operating conditions, the rate of methanol conversion and the selectivity of DME are governed by the physiochemical properties of the catalytic materials. Side reactions such as Fischer-Tropsch (FT), water gas shift, methanation and coke formation may cause lower DME selectivity in the STD process. Therefore, the catalyst must have the ability to suppress these side reactions to enhance DME selectivity. 
Currently $\mathrm{Cu}-\mathrm{ZnO}-\mathrm{Al}_{2} \mathrm{O}_{3}$ catalyst, containing $\mathrm{Cu}$ and $\mathrm{Zn}$ in a ratio of $70: 30$, is used in industrial process for methanol synthesis [12-13]. It is known from the literature that the presence of $\mathrm{Cu}$ in metallic $\mathrm{Cu}^{0}$ form with high degree of dispersity is essential to achieve high selectivity for methanol formation [14]. $\mathrm{Cu}$ dispersion and its intrinsic activity are beneficially influenced by the homogeneous presence of $\mathrm{ZnO}$ in the catalyst. The latter component acts as a geometrical spacer between $\mathrm{Cu}$ nanoparticles [15] which helps to disperse $\mathrm{Cu}$ in course of catalyst preparation [12], and hence to achieve high surface area of $\mathrm{Cu}$. High surface area of $\mathrm{Cu}$ per unit weight of catalyst is necessary to achieve high selectivity in methanol formation. Additionally strong metal-support interaction (SMSI) between $\mathrm{ZnO}$ and $\mathrm{Cu}$ is believed to affect the in situ formation of catalytically active sites. Recently, Behrens and co-workers have reported that $\mathrm{ZnO}$ promoted SMSI with $\mathrm{Cu}$, which induced the formation of "methanol active copper". Different models for this synergy have been discussed in the literature [16, 17-20]. The defect sites in the catalysts can also influence methanol formation [16].

Variation of reaction parameters during catalyst preparation may lead to the formation of different hydroxycarbonate precursor phases, most preferred being zincian-malachite $(\mathrm{Cu}, \mathrm{Zn})_{2}(\mathrm{OH})_{2} \mathrm{CO}_{3}$ [12]. It is well known that incorporation of $\mathrm{Zn}^{2+}$ into the crystal lattice of malachite favors aggregation of the $\mathrm{CuO} / \mathrm{ZnO}$ nanostructuring upon calcination due to the favorable distribution of both the species in the crystal lattice of the precursor compound [21]. However, incorporation of $\mathrm{Zn}^{2+}$ into the malachite crystal lattice is also limited to $<30 \%$ due to chemical constraints [22]. Small amount of $\mathrm{Al}_{2} \mathrm{O}_{3}$ acts as a structural promoter in the methanol synthesis catalyst [23-24], though $\mathrm{Al}^{3+}$ incorporation into the malachite structure can cause charge mismatch. Rather $\mathrm{MgO}$ can be an interesting replacement for $\mathrm{Al}^{3+}$ because of similar charge of $\mathrm{Mg}^{2+}$ and $\mathrm{Zn}^{2+}$, and only $2 \%$ less ionic radii of $\mathrm{Mg}^{2+}$ as compared to $\mathrm{Cu}^{2+}$. Thus, more $\mathrm{Cu}$ dispersion per unit weight of catalyst can be expected in the presence of $\mathrm{MgO}$. Recent studies have shown that $\mathrm{MgO}$ has potential to serve as an effective structural promoter, demonstrating its ability to reduce the reaction temperature, and hence to (i) achieve high selectivity for the desired products by lowering byproducts formation, (ii) inhibit premature catalyst sintering, (iii) improve conversion rates of substrates and (iv) increase active metal surface area [25-26]. Fitzpatrick et al. have reported that the activity of the $\mathrm{Cu}-\mathrm{ZnO}$ catalyst for methanol synthesis improved significantly in the presence of $\mathrm{MgO}$ [27]. The presence of $\mathrm{MgO}$ in the catalyst also reduced by-products formation. Among several promoters $\left(\mathrm{SiO}_{2}, \mathrm{MnO}, \mathrm{Al}_{2} \mathrm{O}_{3}, \mathrm{MgO}\right)$ tested, the authors reported that the highest $\mathrm{Cu}$ surface area and methanol selectivity was achieved by the catalyst that contained $1.5 \mathrm{wt} \% \mathrm{MgO}$.

Subsequent dehydration of methanol to DME takes place in the presence of an acidic catalyst. Solid acid catalysts, such as HZSM-5, H-beta, SAPO's, $\gamma-\mathrm{Al}_{2} \mathrm{O}_{3}, \mathrm{TiO}_{2}, \mathrm{SiO}_{2}-\mathrm{Al}_{2} \mathrm{O}_{3}$ and $\mathrm{Al}_{2} \mathrm{O}_{3}-\mathrm{TiO}_{2}$ have been used for the dehydration of methanol in the temperature range of $250-400{ }^{\circ} \mathrm{C}$ 
[28-31]. Mao et al. have studied the activity of a bifunctional catalytic system, containing $\mathrm{MgO}$ modified HZSM-5 and $\mathrm{Cu} / \mathrm{ZnO} / \mathrm{Al}_{2} \mathrm{O}_{3}$ for direct conversion of syn-gas to DME [32]. The authors revealed that $\mathrm{MgO}$ helped in neutralizing the stronger acid sites to weaker sites. The strong acidic sites are reported to enhance DME degradation to lower hydrocarbons [10].

Although Mao et al. have reported the beneficial effect of $\mathrm{MgO}$ for methanol dehydration, the role of $\mathrm{MgO}$ in the bifunctional catalyst for the STD process is yet to be investigated. Therefore, it is worthy to study the effect of $\mathrm{MgO}$ on the properties of the hybrid $\mathrm{Cu} / \mathrm{ZnO} / \mathrm{MgO}-\gamma-\mathrm{Al}_{2} \mathrm{O}_{3}$ catalyst and its catalytic effectiveness for direct conversion of syn-gas to DME. Additionally, we studied the combined effects of $\mathrm{ZnO}$ and $\mathrm{MgO}$ on the $\mathrm{Cu}$-based hybrid ternary catalytic systems by changing the weight ratio of $\mathrm{ZnO}$ and $\mathrm{MgO}$ in the catalyst compositions.

Among three different acidic materials $\left(\gamma-\mathrm{Al}_{2} \mathrm{O}_{3}, \mathrm{HZSM}-5, \mathrm{SiO}_{2}-\mathrm{Al}_{2} \mathrm{O}_{3}\right)$ used in the formulation of the hybrid catalysts, $\gamma-\mathrm{Al}_{2} \mathrm{O}_{3}$ was found to be most effective in combination with $\mathrm{Cu} / \mathrm{ZnO} / \mathrm{MgO}$, which showed constant methanol conversion over a longer reaction time with high selectivity in DME. Thus, $\gamma-\mathrm{Al}_{2} \mathrm{O}_{3}$ was selected as a component for methanol dehydration in the hybrid catalyst. Furthermore, it is known that $\gamma-\mathrm{Al}_{2} \mathrm{O}_{3}$ can resist structural changes during methanol dehydration because of its high hydrothermal stability, and thus minimize the formation of undesired side products [33-34]. The focus of this study is to evaluate the structural and physicochemical properties of the catalysts as a function of $\mathrm{MgO}$ content and the effect of these catalytic properties on the conversion of syn-gas, and DME yield and selectivity.

\section{EXPERIMENTAL SECTION}

\subsection{Chemicals}

Copper nitrate $\left(\mathrm{Cu}\left(\mathrm{NO}_{3}\right)_{2} \cdot 2.5 \mathrm{H}_{2} \mathrm{O}\right)$, zinc nitrate $\left(\mathrm{Zn}\left(\mathrm{NO}_{3}\right)_{2} \cdot \mathrm{XH}_{2} \mathrm{O}\right)$ were purchased from Alfa Aesar. Magnesium nitrate $\left(\mathrm{Mg}\left(\mathrm{NO}_{3}\right)_{2} \cdot 6 \mathrm{H}_{2} \mathrm{O}\right)$ and sodium carbonate were obtained from Acros India and Merck India, respectively. All chemicals were used as received.

$\mathrm{CuO} / \mathrm{ZnO} / \mathrm{MgO}$ was prepared by a co-precipitation method. A $1000 \mathrm{~mL}$ aqueous solution containing copper nitrate, zinc nitrate and/or magnesium nitrate salts of total molarity of 1.0 and a $500 \mathrm{~mL}$ aqueous solution of $\mathrm{Na}_{2} \mathrm{CO}_{3}$ of $0.5 \mathrm{M}$ were mixed in drop wise fashion in a $2 \mathrm{~L}$ jacketed reactor containing $500 \mathrm{~mL}$ of distilled water. The jacketed reactor (Figure S1) was stirred continuously at $350 \mathrm{rpm}$ and $70{ }^{\circ} \mathrm{C}$ during mixing of the two solutions. The $\mathrm{pH}$ of the mixture was maintained at 7 during precipitation by controlling the flow rates of the two solutions. After complete precipitation, the precipitates were aged for $1 \mathrm{~h}$ at $70{ }^{\circ} \mathrm{C}$. The precipitate was then filtered and washed several times with distilled water to remove residual sodium ions. Complete removal of 
$\mathrm{Na}^{+}$and other ions was confirmed by the conductivity measurement of the filtrate. The precipitate was washed until the conductivity of the filtrate was similar to that of distilled water. The washed solid was dried at $80{ }^{\circ} \mathrm{C}$ in a furnace for $12 \mathrm{~h}$ and subsequently calcined under air at $400{ }^{\circ} \mathrm{C}$ for $4 \mathrm{~h}$. Other catalysts (Table 1) were prepared by following the similar procedure. The atomic percentage of each metal in the catalyst, as listed in Table 1, represents their theoretical values. Hereafter, the catalysts are represented by the presence of metal components wherein $\mathrm{Cu}, \mathrm{Zn}$ and $\mathrm{Mg}$ are abbreviated as $\mathrm{C}, \mathrm{Z}$ and $\mathrm{M}$, respectively. The value in parenthesis represents the percentage of $\mathrm{Mg}$ in the catalyst. The hybrid catalysts were prepared by grinding as-synthesized CZM catalysts and $\gamma$ $\mathrm{Al}_{2} \mathrm{O}_{3}$ in 2:1 weight ratio in an analytical mill (IKA, Germany). The resultant powder was then pressed into pellets by using a $\mathrm{KBr}$ pelletizer. Henceforth, methanol synthesis catalysts, e.g, CZM, and methanol dehydration catalysts, e.g. $\gamma-\mathrm{Al}_{2} \mathrm{O}_{3}$ are abbreviated as MSC and MDC, respectively.

\begin{tabular}{cccc}
\hline \multicolumn{4}{l}{ Table 1. Compositions of the as-synthesized CZM catalysts. } \\
\hline Catalysts & $\mathrm{Cu}($ atom \%) & Zn (atom \%) & Mg (atom \%) \\
$\mathrm{CZM}(0)$ & 55 & 45 & 0 \\
$\mathrm{CZM}(5)$ & 55 & 40 & 5 \\
$\mathrm{CZM}(10)$ & 55 & 35 & 10 \\
$\mathrm{CZM}(20)$ & 55 & 25 & 20 \\
$\mathrm{CZM}(30)$ & 55 & 15 & 30 \\
\hline
\end{tabular}

\subsection{Instrumentation}

Surface area measurement. Brunauer-Emmett-Teller (BET) surface area of the catalyst samples was determined by a multipoint $\mathrm{N}_{2}$ adsorption-desorption method using Micromeritics ASAP 2020 analyzer. The pore volume was determined at a relative $\mathrm{N}_{2}$ pressure $\left(\mathrm{p} / \mathrm{p}_{0}\right)$ of 0.99 . In each of the typical measurement, approximately $100 \mathrm{mg}$ of calcined hybrid catalyst sample was taken in a glass reactor and degassed under helium at $300^{\circ} \mathrm{C}$ for $3 \mathrm{~h}$ at a heating rate of $10^{\circ} \mathrm{C} / \mathrm{min}$.

Power X-ray Diffraction (XRD). The powder X-Ray diffraction patterns of the investigated catalysts were obtained from Philips X'Pert $(40 \mathrm{kV}, 30 \mathrm{~mA})$ X-ray diffractometer equipped with $\mathrm{Cu} \mathrm{K} \alpha$ radiation source $(\lambda=1.542)$ and a nickel filter in the $2 \theta$ range of $10^{\circ}-70^{\circ}$ at a scanning speed of $5 \% \mathrm{~min}$. Sample preparation for the X-ray analysis involved gentle grinding of the solid into a fine powder and packing of approximately $0.5-0.8 \mathrm{~g}$ of powder into an aluminium sample holder with light compression to make it flat and tight.

Temperature Programmed Desorption of Ammonia ( $\mathbf{N H}_{3}$-TPD). $\mathrm{NH}_{3}$-TPD measurement of the catalyst samples was performed on Thermo Fischer Scientific TPD/R/O (1100 series) analyzer to determine the surface acidity. In each of the typical analysis, approximately 100 
mg of the sample was loaded in a quartz cell and initially flushed with a He gas flow at $400{ }^{\circ} \mathrm{C}$ for 2 $\mathrm{h}$, cooled to $150{ }^{\circ} \mathrm{C}$ and then saturated with ammonia at the same temperature for 30 minutes at a flow rate of $20 \mathrm{~mL} / \mathrm{min}$. After exposure to ammonia, the catalyst samples were subsequently purged with the He flow and the temperature was raised up to $800{ }^{\circ} \mathrm{C}$ at a linear heating rate of $10{ }^{\circ} \mathrm{C} / \mathrm{min}$ for measuring desorbed $\mathrm{NH}_{3}$ by using a thermal conductivity detector (TCD).

Temperature Programmed Reduction Study (TPR). TPR study of the catalyst samples was performed on the same instrument used for TPD studies to determine the reduction behavior of the materials. In this analysis, approximately $20 \mathrm{mg}$ of each sample was loaded in a U-shaped glass cell and the sample was flushed with a Ar gas at a flow rate of $30 \mathrm{~mL} / \mathrm{min}$ and at $150{ }^{\circ} \mathrm{C}$ for $2 \mathrm{~h}$, following which the sample was cooled down to $50{ }^{\circ} \mathrm{C}$ at a rate of $10{ }^{\circ} \mathrm{C} / \mathrm{min}$. The sample was then heated up to $900{ }^{\circ} \mathrm{C}$ at a heating rate of $10{ }^{\circ} \mathrm{C} / \mathrm{min}$ in the presence of a mixture of $5 \% \mathrm{H}_{2}$ in Ar.

Scanning Electron Microscopy (SEM). The surface morphology of the catalyst samples was characterized by VEGA LSU (TESCAN) SEM analyzer. The image was obtained at a magnification of $1100 \mathrm{X}$ and at $15 \mathrm{kV}$ (kilovolt) using a secondary electron detector.

Transmission Electron Microscopy (TEM). TEM images and selected area electron diffraction (SAED) analyses were performed on a JEOL JEM 2010 transmission electron microscope operated at an accelerating voltage of $200 \mathrm{kV}$. Samples for TEM analyses were prepared by applying one drop dispersed solution of the sample onto the carbon coated $\mathrm{Cu}$ grid and allowing the solvent to slowly evaporate at room temperature.

Turn-over frequencies (TOFs). TOF values for all hydride catalysts were calculated from the rates of $\mathrm{CO}$ consumption measured from catalytic experiments. The number of active catalyst sites used for TOF calculation were measured from $\mathrm{H}_{2}$-chemisorption study in which the adsorbatefree reduced catalyst sample was cooled down to $50{ }^{\circ} \mathrm{C}$ in a He stream and then saturated with $\mathrm{H}_{2}$ gas for minimum 60 minutes. The sample was further cooled down to $-195{ }^{0} \mathrm{C}$ by using liquid nitrogen, and residual $\mathrm{H}_{2}$ was flushed out with a He flow. The temperature-programmed desorption experiment was carried out by ramping the temperature up to $350{ }^{\circ} \mathrm{C}$ at a heating rate of $2{ }^{\circ} \mathrm{C} / \mathrm{min}$.

\subsection{Catalysis experiments}

The catalytic effectiveness of all bifunctional hybrid catalysts were tested by using a high pressure fixed bed tubular reactor (Figure 1). Typically, $12 \mathrm{~g}$ of catalyst in the form of oxide pellet (450-600 microns) was placed in the middle of the reactor tube. The catalyst occupied about $10 \mathrm{~cm}$ length of the reactor and the remaining length of the tube was filled with inert glass beads from both sides to keep the catalyst bed fixed in the middle. The glass beds act as a preheating zone for the feed gases. As shown in figure 1, the test reactor set up is equipped with a gas feeding system, 
tubular furnace, mass flow controllers (MFC), back pressure regulator, product recovery and separation system and a gas outflow measuring section.

\section{Bench scale unit for Syngas to DME}

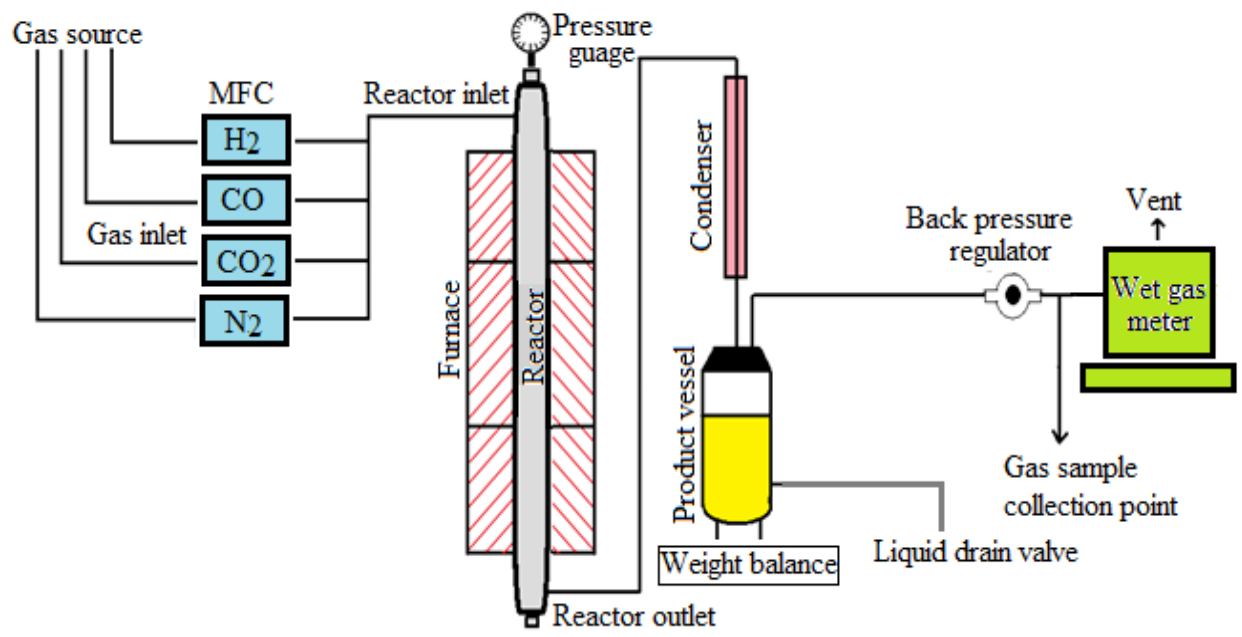

Figure 1. Schematic diagram of a tubular reactor for bench scale conversion of syn-gas to DME.

Before catalysis, the loaded catalyst in the reactor was first subjected to a one stage activation process in which the catalyst was reduced with a stream of pure $\mathrm{H}_{2}$ at $300{ }^{\circ} \mathrm{C}$ for $5 \mathrm{~h} . \mathrm{H}_{2}$ and $\mathrm{CO}$ gases in 1.5:1 ratio were then fed into the reactor through separate mass flow controllers. As the feed stream passed through the inert beds, it was heated to achieve the desired temperature. Effluent stream leaving from the bottom of the reactor passed through a condenser to a product separator. Condensed liquid product stream was separated from the non-condensable gases in the separator. A back pressure regulator (BPR) was placed in the separator to regulate the system pressure. The gaseous effluents leaving the separator through the BPR passed through a wet gas meter, which measured the volumetric flow rate. Most of the reactions were performed under the operating reactor pressure of 30 bar with a space velocity of $2000 \mathrm{ml} / \mathrm{g}_{\text {cat }} \cdot$ hr and at $260{ }^{\circ} \mathrm{C}$. The experiments were also performed by varying the reaction temperature, pressure, space velocity and $\mathrm{H}_{2} / \mathrm{CO}$ ratio in the range of $240-260{ }^{\circ} \mathrm{C}, 30-50 \mathrm{bar}, 2000-4000 \mathrm{ml} / \mathrm{g}_{\text {cat }} \cdot \mathrm{hr}$ and $1-3$, respectively. The gaseous products were analyzed by using an Agilent 7890A gas chromatograph equipped with a TCD detector for $\mathrm{CO}$ and $\mathrm{CO}_{2}$ analysis and a FID detector for DME and hydrocarbons analysis. HP Plot-U column was used for analysis of methanol and DME. Haysep Q and Molsieve 13x columns were used for analysis of $\mathrm{H}_{2}$ and $\mathrm{CO} / \mathrm{CO}_{2}$, respectively. $\mathrm{CO}$ conversions and the selectivity of the products were calculated in mol\% by using the following equations.

$$
\text { Conversion of } \mathrm{CO}(\mathrm{mol} \%)=\frac{(\text { inlet moles of } \mathrm{CO}-\text { outlet moles of } \mathrm{CO})}{\text { inlet moles of } \mathrm{CO}} \times 100
$$




$$
\text { Selectivity }(\text { mol\% })=\frac{n_{i} \times \text { moles of produced component }}{(\text { inlet moles of } \mathrm{CO}-\text { outlet moles of CO })} \times 100
$$

where $\mathrm{n}_{\mathrm{i}}$ is the stoichiometric coefficient for each of the product produced.

\section{RESULTS AND DISCUSSION}

\subsection{Surface Properties}

The surface properties of all the catalyst samples containing MSC and MDC components and their catalytic activities (turnover frequency (TOF), CO conversions) are presented in Table 2. Surface area of the catalysts was calculated by applying the multipoint BET method whereas pore volume was calculated from BJH method using desorption branch of the isotherm. The surface area of the catalysts, determined from multipoint $\mathrm{N}_{2}$ adsorption-desorption isotherm studies (Figure $\mathrm{S} 2 \mathrm{a}$ ), was found to increase linearly from $79.2 \mathrm{~m}^{2} / \mathrm{g}$ to $95.9 \mathrm{~m}^{2} / \mathrm{g}$ as the $\mathrm{MgO}$ content in the catalysts increased from 0 to $20 \%$. The highest surface area of the $\mathrm{CZM}(20)-\gamma-\mathrm{Al}_{2} \mathrm{O}_{3}$ catalyst can be attributed to the promoting behavior of $\mathrm{MgO}$ towards the nanostructuring of $\mathrm{CuO}$ domains. Noteworthy, $\mathrm{CZM}(30)-$ $\gamma-\mathrm{Al}_{2} \mathrm{O}_{3}$ catalyst, containing maximum $\mathrm{MgO}$ loading (30\%), exhibited lowest surface area of 67.1 $\mathrm{m}^{2} / \mathrm{g}$ which may be due to inhibition in nanostructuring phenomenon by excess $\mathrm{MgO}$ during the calcination process. SEM images of the $\mathrm{CZM}(20)-\gamma-\mathrm{Al}_{2} \mathrm{O}_{3}$ catalyst shows an uniform sponge like morphology (Figure S3d). When compared the surface area of the $\mathrm{CZM}(20)-\gamma-\mathrm{Al}_{2} \mathrm{O}_{3}$ and $\mathrm{CZM}(0)-$ $\gamma-\mathrm{Al}_{2} \mathrm{O}_{3}$ catalysts, the surface area of the former catalyst is enhanced by $22 \%$ than the latter. Zander et al. have also reported higher surface area of $20 \% \mathrm{MgO}$ loaded $\mathrm{Cu}$ based methanol synthesis catalyst [21], which is in well agreement with our observation. The $\mathrm{N}_{2}$ adsorption-desorption isotherms, as shown in Figure S2, show a type IV isotherms for all MSC catalysts with an H1-type hysteresis loop, which is characteristic of mesoporous materials having interparticle pores of nanoscale dimensions. The pore size, shown in Table 2, was calculated by employing non local density functional theory (NLDFT) on the respective $\mathrm{N}_{2}$ adsorption-desorption isotherms (Figure S2b).

As seen in Table 2, surface areas of all hybrid catalysts are lower than that of $\gamma-\mathrm{Al}_{2} \mathrm{O}_{3}, \mathrm{MDC}$ component in the catalyst. To study the effect of physical mixing of these two components, we performed surface area analysis of both the components separately. Surface areas of all MSC components were found to be in the range of $16-25 \mathrm{~m}^{2} / \mathrm{g}$, whereas the surface area of MDC component $\left(\gamma-\mathrm{Al}_{2} \mathrm{O}_{3}\right)$ is $230 \mathrm{~m}^{2} / \mathrm{g}$. Thus, the observed surface areas of the hybrid catalysts (67-96 $\mathrm{m}^{2} / \mathrm{g}$ ) are the average values of the surface areas of the MSC and MDC components. These calculations are shown in the supporting information. 
Table 2. Textural and structural properties of the hybrid catalysts containing MSC and MDC components.

\begin{tabular}{ccccccc}
\hline Catalyst & $\begin{array}{c}\text { Surface } \\
\text { area } \\
\left(\mathbf{m}^{\mathbf{2}} / \mathbf{g}\right)\end{array}$ & $\begin{array}{c}\text { Pore size } \\
(\mathbf{n m})\end{array}$ & $\begin{array}{c}\text { Total pore } \\
\text { volume } \\
\left(\mathbf{c m}^{\mathbf{3}} / \mathbf{g}\right)\end{array}$ & $\begin{array}{c}\text { Crystallite } \\
\text { size from } \\
\text { XRD }(\mathbf{n m})\end{array}$ & $\begin{array}{c}\text { TOF } \\
\times \mathbf{1 0}^{-2} \\
\left(\mathbf{s}^{-\mathbf{1}}\right)\end{array}$ & $\begin{array}{c}\text { CO } \\
\text { conversion } \\
(\%)\end{array}$ \\
\hline $\mathrm{CZM}(0)-\gamma-\mathrm{Al}_{2} \mathrm{O}_{3}$ & 79.2 & 9.4 & 0.19 & 13.9 & 1.2 & 19.8 \\
$\mathrm{CZM}(5)-\gamma-\mathrm{Al}_{2} \mathrm{O}_{3}$ & 80.2 & 9.5 & 0.19 & 12.7 & 2.8 & 25.5 \\
$\mathrm{CZM}(10)-\gamma-\mathrm{Al}_{2} \mathrm{O}_{3}$ & 86.5 & 9.4 & 0.21 & 11.9 & 3.5 & 30.6 \\
$\mathrm{CZM}(20)-\gamma-\mathrm{Al}_{2} \mathrm{O}_{3}$ & 95.9 & 8.1 & 0.22 & 8.6 & 8.3 & 46.2 \\
$\mathrm{CZM}(30)-\gamma-\mathrm{Al}_{2} \mathrm{O}_{3}$ & 67.1 & 9.4 & 0.18 & 13.1 & 6.1 & 21.1 \\
$\gamma-\mathrm{Al}_{2} \mathrm{O}_{3}$ & 230.0 & 7.8 & 0.73 & - & - & - \\
\hline
\end{tabular}

\subsection{Crystalline Properties from X-Ray Diffraction}

XRD patterns of the MSC catalysts before and after calcination are shown in Figures $2 \mathrm{a}$ and $2 \mathrm{~b}$, respectively. The results show the formation of single phase materials before calcination with a crystal structure similar to that of well crystalline phase of zincian malachite $(\mathrm{Cu}, \mathrm{Zn})_{2}(\mathrm{OH})_{2} \mathrm{CO}_{3}$ (ICSD: 72-75) which has been reported as a relevant precursor material [35]. Our findings also correspond to the literature reports describing rosasite or malachite as favored precursor phases for catalysts containing atomic $\mathrm{Cu}$ concentration of $>20 \%$ [36]. Subsequent calcination of these malachite type of structures leads to the formation of small $\mathrm{CuO}$ crystallites and more uniformly dispersed $\mathrm{Cu}-\mathrm{Zn}$ oxide phases which are believed to be ideal intermediates of final reduced catalysts [37-38]. The role of $\mathrm{MgO}$ in promoting the formation of malachite can clearly be understood after analyzing the pattern of $\mathrm{CZM}(0)$ catalyst as it precipitated out in the form of a mixed aurichalcite (ISCD: 17-743) and malachite type of structure. Auricalcite material which usually exists in the form of large platelets with unfavorable meso-structure may get reduced at higher temperature [22]. Our TPR results (vide infra) agrees well with the literature observation. In the presence of $\mathrm{MgO}$ in the catalyst matrix, malachite structure was found to form predominantly (Figure 2a), which is considered as the relevant precursor for the preparation of active nanostructured $\mathrm{Cu} / \mathrm{ZnO}[39]$. 

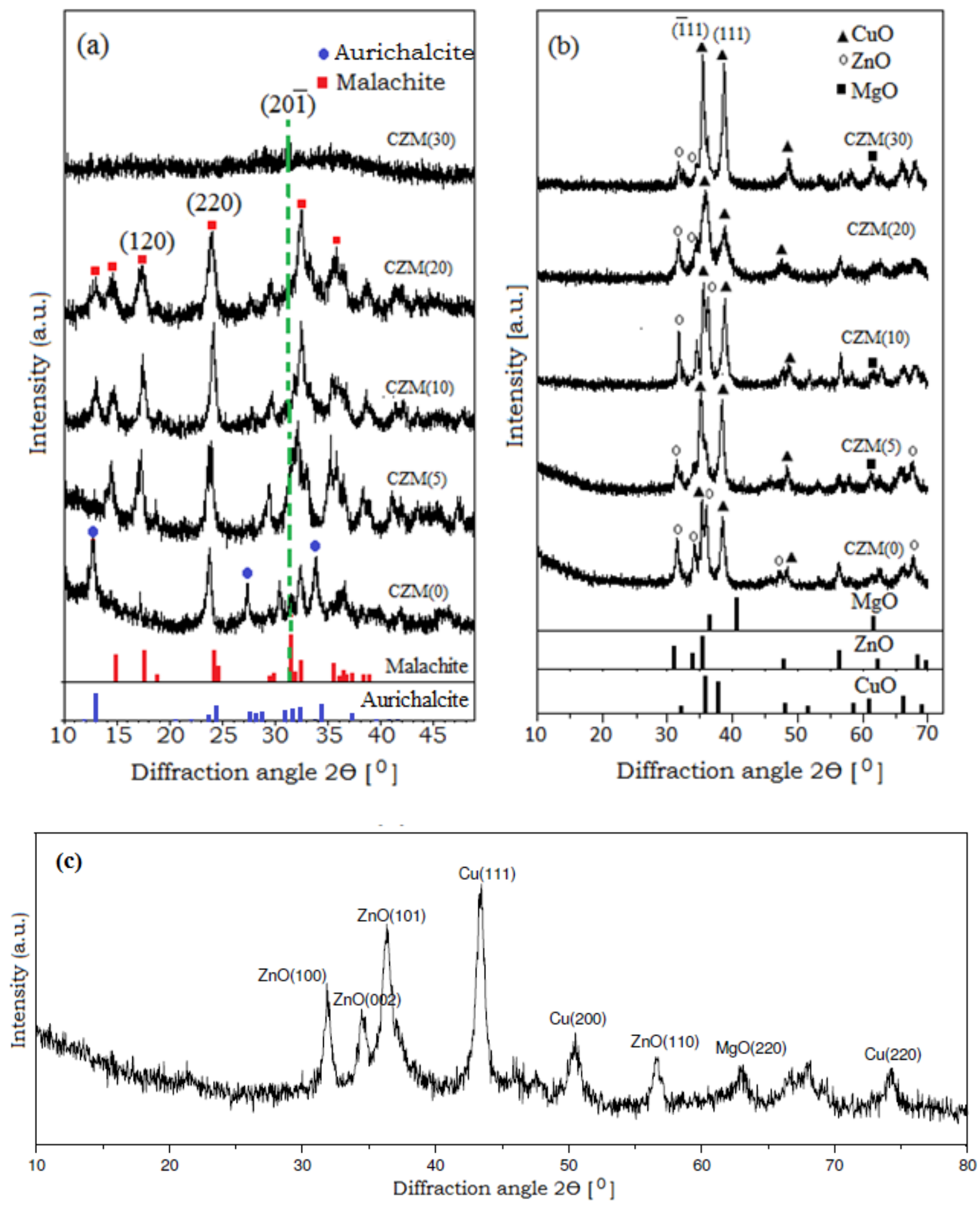

Figure 2. XRD patterns of MSC catalyst before calcination (a) and after calcination (b). Figure 2(c) shows XRD pattern of the reduced form of CZM(20) catalyst after reaction.

When compared with different standard planes of malachite, e.g., (120), (220), (201) , a slight shift of peak associated with $(20 \overline{\mathbf{1}})$ plane at $2 \theta=31.23^{\circ}$ was observed for the prepared catalysts. A shift of $2 \theta$ from $31.23^{\circ}$ to $32.33^{0}, 32.44^{0}, 32.5^{\circ}$ and $32.75^{\circ}$ was observed for $\mathrm{CZM}(0), \mathrm{CZM}(5), \mathrm{CZM}(10)$ 
and $\operatorname{CZM}(20)$, respectively, which may be due to the assimilation of $\mathrm{Mg}^{2+}$ cations in the lattice of malachite, resulting in more $\mathrm{Cu}$ dispersion and high surface area. The maximum peak shift was observed for CZM(20). The observed peak shift of (201) plane for catalysts containing $\mathrm{MgO}$ is also in agreement with the study done by Zander et al. [21], where the authors reported a similar peak shift for $(20 \overline{\mathbf{1}})$ plane in malachite structure when $\mathrm{Zn}^{2+}$ or $\mathrm{Mg}^{2+}$ cations were incorporated into the catalyst matrix. Interestingly, $\mathrm{CZM}(30)$ catalyst containing the maximum amount of $\mathrm{MgO}$ did not show any crystalline peak, which suggests that an amorphous nature of this catalyst dominated by the presence of excess $\mathrm{MgO}$. Perhaps, $\mathrm{MgO}$ formed a layer over the catalyst surface which might have encapsulated the active $\mathrm{Cu}-\mathrm{ZnO}$ sites.

Upon calcination of all MSC catalysts at $400{ }^{\circ} \mathrm{C}$, crystalline $\mathrm{CuO}$ was formed (Figure 2b) and some reflections of $\mathrm{ZnO}$ were observed. This interpretation is based on the standard XRD spectrum of pure $\mathrm{CuO}$ (JCPDS 80-1268), ZnO (JCPDS 36-1451) and MgO (JCPDS 89-7746), which are also included in Figure $2 \mathrm{~b}$, confirming only single species of $\mathrm{Cu}$ was formed after calcination. Reflections at $2 \theta=35.6^{\circ}$ and $38.9^{\circ}$ can be assigned to $(\overline{1} 11)$ and (111) plane of $\mathrm{CuO}$ and indexed to its monoclinic phase. Likewise, reflections at $2 \theta=31.9^{\circ}$ and $36.2^{\circ}$ can be assigned to hexagonal phase of $\mathrm{ZnO}$. However, after adding $\mathrm{MgO}$, many $\mathrm{ZnO}$ reflection peaks were overlapped with those of $\mathrm{CuO}$, suggesting a well dispersed mixture of $\mathrm{CuO}-\mathrm{ZnO}$ is present in the catalysts when $\mathrm{MgO}$ was added. The absence of standard reflections for $\mathrm{MgO}$ at $2 \theta=37.5,43.0$ and $62.6^{0}$ might be attributed their amorphous nature.

The average crystallite size of the $\mathrm{CuO}$ phase in calcined catalyst was estimated by applying Scherrer's equation to the $\mathrm{CuO}$ peak at $2 \theta=38.9^{\circ}$ corresponding to (111) plane and these values are shown in Table 2. Among all the catalysts, $\operatorname{CZM}(20)$ exhibits low intensity broader peaks owing to the presence of small crystallites. The crystallite size of $\mathrm{CuO}$ increased in the $\mathrm{CZM}(30)$ catalyst which contained highest amount of $\mathrm{MgO}(30 \%)$. Such an increase in the size may result in a decrease of active $\mathrm{Cu}^{0}$ sites in the reduced catalyst, which is believed to be the active sites for methanol synthesis [40].

XRD pattern of the reduced form of $\mathrm{CZM}(20)-\gamma-\mathrm{Al}_{2} \mathrm{O}_{3}$ after reaction is shown in Figure 2c. It shows characteristic peaks for cubic metallic $\mathrm{Cu}(\mathrm{JCPDS} 04-0836)$ at $2 \theta=43.5^{\circ}, 50.4^{\circ}$ and $74.2^{\circ}$, suggesting $\mathrm{CuO}$ in the catalyst was converted to active $\mathrm{Cu}$ after reaction. However, $\mathrm{ZnO}$ and $\mathrm{MgO}$ retained their oxidation state, as evidenced from their characteristic XRD peaks, which is important to maintain dispersion of metallic copper in the catalyst during methanol synthesis.

\subsection{Acid Density from $\mathrm{NH}_{3}-\mathrm{TPD}$ Measurement}


$\mathrm{NH}_{3}$ is widely used as a molecular probe for measuring total acid density of acidic materials because of its selective interaction with both Brönsted and Lewis acid sites. In this experiment, $\mathrm{NH}_{3}$ was first allowed to absorb on the surface of the hybrid catalysts and then $\mathrm{NH}_{3}$ was desorbed from the acidic sites as the temperature of $\mathrm{NH}_{3}$-adsorbed material gradually increased. Usually, desorption of $\mathrm{NH}_{3}$ at lower and higher temperatures are expected from weaker and stronger acidic sites [41]. $\mathrm{NH}_{3}$-TPD profile of all hybrid catalysts show three desorption peaks in the temperature range of $145-148{ }^{\circ} \mathrm{C}(\mathrm{T} 1), 270-335^{\circ} \mathrm{C}(\mathrm{T} 2)$ and $519-600{ }^{\circ} \mathrm{C}(\mathrm{T} 3)$ (Figure 3), presumably due to the presence of weak, medium and strong acid sites in the materials. The corresponding acid density values at each peak and their acid density percentage contribution towards total acidity are tabulated in Table 3. These data show that the total acidity of the catalysts decreased in the order of CZM(0)$\gamma-\mathrm{Al}_{2} \mathrm{O}_{3}>\mathrm{CZM}(5)-\gamma-\mathrm{Al}_{2} \mathrm{O}_{3}>\mathrm{CZM}(10)-\gamma-\mathrm{Al}_{2} \mathrm{O}_{3}>\mathrm{CZM}(20)-\gamma-\mathrm{Al}_{2} \mathrm{O}_{3}>\mathrm{CZM}(30)-\gamma-\mathrm{Al}_{2} \mathrm{O}_{3}$, whereas medium acidity at T2 decreased in the order of $\mathrm{CZM}(20)-\gamma-\mathrm{Al}_{2} \mathrm{O}_{3}>\mathrm{CZM}(30)-\gamma-\mathrm{Al}_{2} \mathrm{O}_{3}>\mathrm{CZM}(10)-$ $\gamma-\mathrm{Al}_{2} \mathrm{O}_{3}>\mathrm{CZM}(5)-\gamma-\mathrm{Al}_{2} \mathrm{O}_{3}>\mathrm{CZM}(0)-\gamma-\mathrm{Al}_{2} \mathrm{O}_{3}$. On the other hand, acid density at $\mathrm{T} 3$ showed decreasing trend as the amount of $\mathrm{MgO}$ in the catalysts increased. However, due to the opposite trends of medium and strong acidity values of the catalysts, the total acidity values show a slight decreasing trend as a function of $\mathrm{MgO}$ content, which could be primarily dominated by the basicity of $\mathrm{MgO}$.

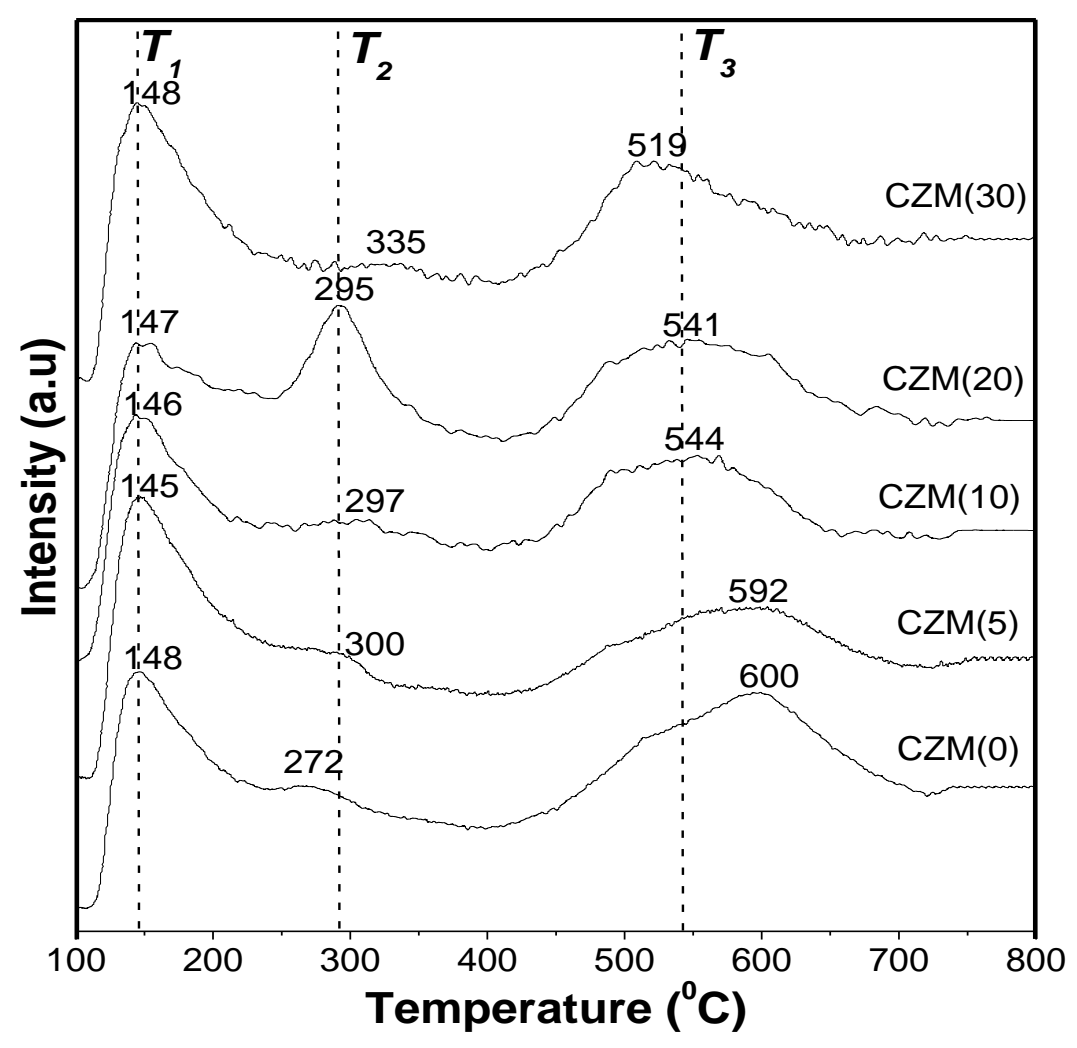

Figure 3. $\mathrm{NH}_{3}-\mathrm{TPD}$ profiles of the hybrid catalysts after calcination. 
$\mathrm{MgO}$ altered the nature of acidic sites in the catalyst. It is because of strong basic property of $\mathrm{MgO}$ which primarily targeted the stronger acidic sites, thus ultimately reduced or modified the stronger acid sites to the moderate or weaker sites. As shown in Table 3, the value of moderate acidic sites increased from $32 \%$ in $\mathrm{CZM}(0)-\gamma-\mathrm{Al}_{2} \mathrm{O}_{3}$ to $45 \%$ in $\mathrm{CZM}(20)-\gamma-\mathrm{Al}_{2} \mathrm{O}_{3}$, but decreased to $36 \%$ in the catalyst containing $30 \% \mathrm{MgO}$. The moderate acid density of $\mathrm{CZM}(20)-\gamma-\mathrm{Al}_{2} \mathrm{O}_{3}$ catalyst is about $42 \%$ higher than the $\mathrm{CZM}(0)-\gamma-\mathrm{Al}_{2} \mathrm{O}_{3}$. It is believed that moderate acidic sites catalyze methanol dehydration to DME, whereas stronger acid sites enhance the formation of undesired hydrocarbons and coke [42]. Thus, $\mathrm{CZM}(20)-\gamma-\mathrm{Al}_{2} \mathrm{O}_{3}$ catalyst is expected to show higher selectivity towards DME formation. It is important to note that the extent of modification of all the hybrid catalysts containing the same amount of $\gamma-\mathrm{Al}_{2} \mathrm{O}_{3}$ is largely dependent on the amount of $\mathrm{MgO}$.

Table 3. $\mathrm{NH}_{3}$-desorption properties of the hybrid catalysts.

\begin{tabular}{l|cc|cc|cc|c}
\hline \multirow{2}{*}{ Catalyst } & \multicolumn{7}{|c}{ Acid density (mmol of NH3/g of catalyst) } \\
\cline { 2 - 8 } & \multicolumn{2}{|c|}{ Weak (T1) } & $(\%)$ & \multicolumn{2}{|c}{ Medium (T2) } & $(\%)$ & \multicolumn{2}{l}{ Strong (T3) (\%) } & Total \\
\hline $\mathrm{CZM}(0)-\gamma-\mathrm{Al}_{2} \mathrm{O}_{3}$ & 0.37 & $(47.6)$ & 0.25 & $(31.6)$ & 0.16 & $(20.8)$ & 0.78 \\
$\mathrm{CZM}(5)-\gamma-\mathrm{Al}_{2} \mathrm{O}_{3}$ & 0.35 & $(45.7)$ & 0.27 & $(36.2)$ & 0.14 & $(18.1)$ & 0.76 \\
$\mathrm{CZM}(10)-\gamma-\mathrm{Al}_{2} \mathrm{O}_{3}$ & 0.34 & $(45.5)$ & 0.29 & $(39.4)$ & 0.12 & $(15.1)$ & 0.75 \\
$\mathrm{CZM}(20)-\gamma-\mathrm{Al}_{2} \mathrm{O}_{3}$ & 0.31 & $(41.2)$ & 0.33 & $(44.7)$ & 0.1 & $(14.1)$ & 0.74 \\
$\mathrm{CZM}(30)-\gamma-\mathrm{Al}_{2} \mathrm{O}_{3}$ & 0.38 & $(52.7)$ & 0.26 & $(36.1)$ & 0.08 & $(11.3)$ & 0.72 \\
$\gamma-\mathrm{Al}_{2} \mathrm{O}_{3}$ & 0.77 & $(44.3)$ & 0.6 & $(38.5)$ & 0.37 & $(21.2)$ & 1.74 \\
\hline
\end{tabular}

\subsection{Reduction Behavior of Catalysts}

The catalytic performance of the bifunctional hybrid catalyst depends on the reducibility of copper as well as their acidity [4,43]. Figure 4 illustrates the degree of copper reduction of the $\mathrm{CZM}-\gamma-\mathrm{Al}_{2} \mathrm{O}_{3}$ catalysts. Based on the results obtained from XRD analysis of the calcined catalyst samples (Figure 2), it is confirmed that $\mathrm{Cu}$ is present in the form of $\mathrm{CuO}$ only. The TPR pattern of the $\mathrm{CZM}(0)-\gamma-\mathrm{Al}_{2} \mathrm{O}_{3}$ catalyst shows two distinct peaks at 263 and $428{ }^{\circ} \mathrm{C}$, suggesting that $\mathrm{CuO}$ in the catalyst undergoes reduction to metallic $\mathrm{Cu}$ in two stages i.e. $\mathrm{Cu}^{2+} \rightarrow \mathrm{Cu}^{+} \rightarrow \mathrm{Cu}^{0}$ [44]. This result also shows that $\mathrm{CZM}(0)-\gamma-\mathrm{Al}_{2} \mathrm{O}_{3}$ possess non-uniformly dispersed active $\mathrm{Cu}^{0}$ sites. On the other hand, the TPR pattern of the catalysts containing $\mathrm{MgO}$ i.e. $\mathrm{CZM}(5)-\gamma-\mathrm{Al}_{2} \mathrm{O}_{3}, \mathrm{CZM}(10)-\gamma-\mathrm{Al}_{2} \mathrm{O}_{3}$, $\mathrm{CZM}(20)-\gamma-\mathrm{Al}_{2} \mathrm{O}_{3}$ and $\mathrm{CZM}(30)-\gamma-\mathrm{Al}_{2} \mathrm{O}_{3}$ showed a single broad reduction peak, suggesting onestage reduction behavior of $\mathrm{CuO}$ to metallic copper [45]. This interpretation agrees well with the XRD spectrum of used $\mathrm{CZM}(20)-\gamma-\mathrm{Al}_{2} \mathrm{O}_{3}$ showing the presence of metallic $\mathrm{Cu}$ (Figure $2 \mathrm{c}$ ). The presence of $\mathrm{MgO}$ in the catalysts might have facilitated the fast reduction of $\mathrm{CuO}$, resulting in 
broadening of the reduction peak. This reduction behavior may also be attributed to the promoting effect of $\mathrm{MgO}$ in favoring the nanostructuring of $\mathrm{CuO}$ and its easy availability on the catalyst surface.

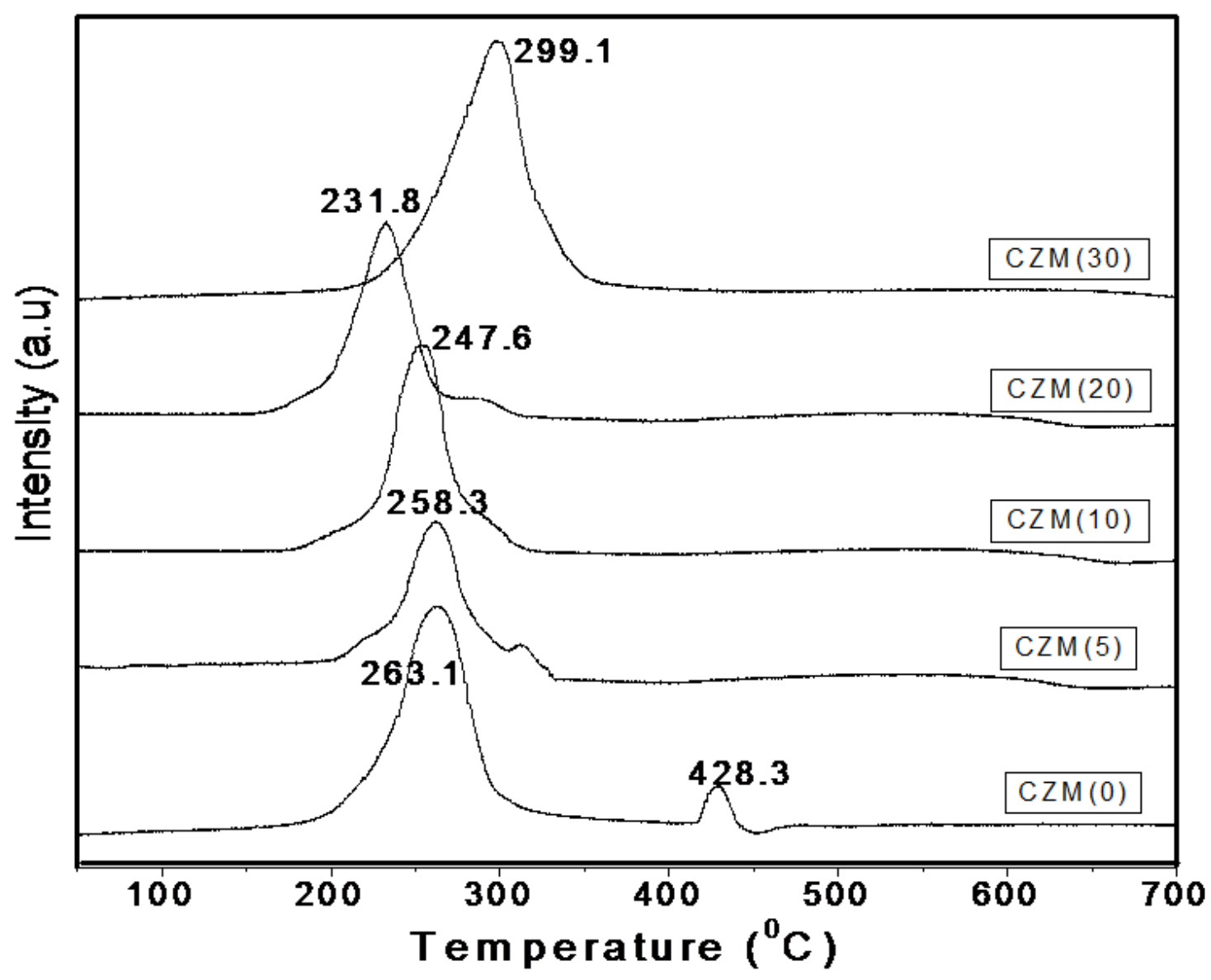

Figure 4. $\mathrm{H}_{2}$-TPR profiles of the hybrid catalysts after calcination.

Additionally, reduction peak of the catalysts containing CZM(5), CZM(10) and CZM(20) shifted considerably towards lower reduction temperatures as the amount of $\mathrm{MgO}$ increased, indicating an accessibility of more $\mathrm{CuO}$ to the reducing gas from the catalysts surface, owing to the structural modification of the catalyst by $\mathrm{MgO}$. The observed reduction temperature of all $\mathrm{MgO}$ incorporated $\mathrm{CZM}-\gamma-\mathrm{Al}_{2} \mathrm{O}_{3}$ catalysts is lower than that of reported reduction temperature $\left(336{ }^{\circ} \mathrm{C}\right)$ of $\mathrm{Al}_{2} \mathrm{O}_{3}$ (3.3 wt\%) incorporated $\mathrm{Cu}-\mathrm{ZnO}$ (abbreviated as $\mathrm{CZA}$ ) bifunctional catalyst [45]. Lower reduction temperatures facilitate easy conversion of $\mathrm{CuO}$ to metallic copper without changing the structural integrity of the catalyst. Thus, $\mathrm{MgO}$ is a better additive for making the catalyst more active by lowering the reduction temperature significantly. It is also seen from Figure 4 that $\mathrm{CZM}(30)-\gamma-\mathrm{Al}_{2} \mathrm{O}_{3}$, containing maximum amount of $\mathrm{MgO}$, shows reduction peak at comparatively higher temperature $\left(299^{\circ} \mathrm{C}\right)$ than those of other $\mathrm{CZM}-\gamma-\mathrm{Al}_{2} \mathrm{O}_{3}$ materials, which may be attributed to the presence of excess non-reducible $\mathrm{MgO}$. Furthermore, higher reduction temperature of 
$\mathrm{CZM}(30)-\gamma-\mathrm{Al}_{2} \mathrm{O}_{3}$ than that of $\mathrm{CZM}(0)-\gamma-\mathrm{Al}_{2} \mathrm{O}_{3}\left(263{ }^{\circ} \mathrm{C}\right)$ could attribute to the fact that excess $\mathrm{MgO}$ might have blocked the accessibility of the reducing gas to $\mathrm{CuO}$. The higher crystallite size of the $\mathrm{CZM}(30)-\gamma-\mathrm{Al}_{2} \mathrm{O}_{3}\left(13.1 \mathrm{~nm}\right.$, Table 2) than those of other $\mathrm{MgO}$ containing $\mathrm{CZM}-\gamma-\mathrm{Al}_{2} \mathrm{O}_{3}$ materials could also contribute to its higher reduction temperature as observed by Agrell et al [46]. The authors reported that large crystallites tend to be reduced more slowly than the smaller ones due to the relatively lower surface area exposed to $\mathrm{H}_{2}$ [46]. Since the catalysts containing $\mathrm{CZM}(0)$, $\mathrm{CZM}(5)$ and $\mathrm{CZM}(30)$ components have higher crystallite size and insufficient amount of $\mathrm{ZnO}$ as a geometrical spacer as compared to $\mathrm{CZM}(10)$ and $\mathrm{CZM}(20)$ analogues, early deactivation for the former materials may be expected because $\mathrm{CuO}$ particles might not be well dispersed and present in agglomerated form.

The observed reduction behavior of the hybrid catalysts can also be explained on the basis of amount of promoter $(\mathrm{MgO})$ and co-promoter $(\mathrm{ZnO})$ present in the $\mathrm{CZM}$ components. Since all the CZM materials contained the same amount of $\mathrm{CuO}$, the degree of possible $\mathrm{CuO}-\mathrm{ZnO}, \mathrm{CuO}-$ $\mathrm{MgO}$ and $\mathrm{ZnO}-\mathrm{MgO}$ interactions in the materials, which play an important role for the overall synergy, depends on the amount of $\mathrm{MgO}$ and $\mathrm{ZnO}$. It is known that industrially applied $\mathrm{Cu} / \mathrm{ZnO}$ catalyst, which can be considered as a model system, contains $\mathrm{Cu}$ and $\mathrm{Zn}$ in an optimum ratio of about 70:30 ( 2.33) in the zincian malachite phase [22]. When compared $\mathrm{Cu}$ to $\mathrm{Zn}$ ratio for all $\mathrm{CZM}$ materials in our hybrid catalysts, these values for $\mathrm{CZM}(0)(1.22), \operatorname{CZM}(5)$ (1.38) and $\mathrm{CZM}(10)$ (1.57) are much lower than the reported optimum value of 2.33. Noteworthy, CZM(30) has significantly higher $\mathrm{Cu}$ : $\mathrm{Zn}$ value of 3.66, because of less amount of $\mathrm{ZnO}$, which suggests that the degree of $\mathrm{CuO}-\mathrm{ZnO}$ interaction in it is less than those of other CZM materials. On the other hand, $\mathrm{Cu}: \mathrm{Zn}$ value of the $\mathrm{CZM}(20)$ (2.2) matches well with the reported value of the model system, suggesting that $\mathrm{ZnO}$ and $\mathrm{MgO}$ are present in an optimum ratio in the $\mathrm{CZM}(20)$, and hence this material showed reduction peak at lowest temperature.

Assuming that $\mathrm{Cu}$ is only present as $\mathrm{CuO}$ in the catalysts, as observed from the XRD patterns, the stoichiometry of $\mathrm{H}_{2}$ to $\mathrm{CuO}$ for complete reduction of $\mathrm{CuO}$ to $\mathrm{Cu}^{0}$ should be equal to unity according to equation (1). The TPR data of all hybrid catalysts indeed show the ratio of $\mathrm{H}_{2}$ to $\mathrm{Cu}$ is close to unity (Table 4), which illustrates complete reduction of $\mathrm{CuO}$ at the reduction temperature.

$\mathrm{CuO}+\mathrm{H}_{2} \longrightarrow \mathrm{Cu}+\mathrm{H}_{2} \mathrm{O}$ 
Table 4. TPR data of the hybrid catalysts containing calcined CZM materials.

\begin{tabular}{llll}
\hline Catalyst & $\mathbf{T}_{\mathbf{m a x}}\left({ }^{0} \mathbf{C}\right)$ & $\begin{array}{l}\mathbf{H}_{2} \text { consumption } \\
\left(\mathrm{mmol} \mathrm{H}_{2} \mathrm{~g}^{-1}\right)\end{array}$ & $\mathrm{H}_{2} / \mathrm{Cu}$ \\
\hline $\mathrm{CZM}(0)$ & 263 & 0.59 & 0.99 \\
$\mathrm{CZM}(5)$ & 258 & 0.42 & 0.99 \\
$\mathrm{CZM}(10)$ & 248 & 0.51 & 1.02 \\
$\mathrm{CZM}(20)$ & 232 & 0.77 & 1.03 \\
$\mathrm{CZM}(30)$ & 299 & 0.46 & 1.02 \\
$\mathrm{CZA}^{\mathrm{a}}$ & 336 & n.a & n.a \\
\hline
\end{tabular}

${ }^{\mathrm{a}} \mathrm{Cu}-\mathrm{ZnO}($ Ref 45$) ;$ n.a. = not available.

\subsection{Morphology from SEM and HRTEM}

The surface morphology of the hybrid catalysts containing CZM materials was characterized by SEM technique. Low resolution SEM images of all catalysts (Figure S3), show the formation of spherical particles which are self aggregated to larger particles. Due to the formation of self-assembled larger particles, the catalysts containing $\mathrm{CZM}(0), \operatorname{CZM}(5)$ and $\mathrm{CZM}(30)$ show non-uniform size distribution, whereas the catalysts containing CZM(10) and CZM(20) components have uniform dispersion and size. The magnified SEM image of CZM(20) (Figure S3f) shows a "urchin like" morphology, revealing the presence of spherical granule-type particles. SEM image of CZM(30) (Figure S3e) shows the particles are distorted and irregular, presumably due to the presence of excess $\mathrm{MgO}$ [47].

Selected catalyst samples were subjected to HRTEM analysis: calcined CZM $(0)$-the catalyst with no $\mathrm{MgO}$, calcined $\mathrm{CZM}(20)$-the catalyst with optimum $\mathrm{MgO}$ and the reduced form of CZM(20) after reaction. The TEM images show that the particle sizes are in the range of 11-25 nm. TEM investigation of the calcined and the reduced catalysts showed that the general microstructure of $\mathrm{CZM}(0)$ (Figure 5a) and $\mathrm{CZM}(20)$ (Figure 5b) is similar and characterized by the presence of spherical assembly of $\mathrm{CuO}$ nanoparticles separated by differently sized crystallites of $\mathrm{ZnO}$ and/or $\mathrm{MgO}$ particles indicating the uniformly distributed nanoparticulate microstructures. This nanostructure is preserved (Figure 5c) even after the reduction. The presence of larger $\mathrm{CuO}$ particles in $\mathrm{CZM}(0)$ as compared to $\mathrm{CZM}(20)$ is consistent with difference in surface areas of the two catalysts (Table 2). This result indicates that the $\mathrm{CuO}$ particles are geometrically dispersed in a better way in the presence of MgO. SAED patterns of the catalysts revealed the formation of well crystalline materials. The presence of (111) plane of monoclinic $\mathrm{CuO}$ and (100) (110) and (002) planes of hexagonal wurtzite phase of $\mathrm{ZnO}$ have been identified as major phases in the SAED 
pattern of CZM(0) (Figure 5d), whereas in CZM(20) (Figure 5e), in addition to these planes of CuO and $\mathrm{ZnO}$, (220) plane of cubic $\mathrm{MgO}$ crystallites are clearly seen. Indexing of the SAED pattern was done by calculating $d$-spacing values from the magnified electron diffraction patterns and matching it with the standard values obtained from XRD analysis. The SAED image of the reduced form of $\mathrm{CZM}(20)$ material (Figure 5f) shows the characteristic phases for metallic $\mathrm{Cu}$ and $\mathrm{ZnO}$, suggesting that the reduced form is still in its original non-decomposed active form in the matrix. The high resolution TEM images thus support the arrangement of well dispersed $\mathrm{CuO}$ and $\mathrm{MgO}$ nanoparticles in the $\mathrm{ZnO}$ matrix.

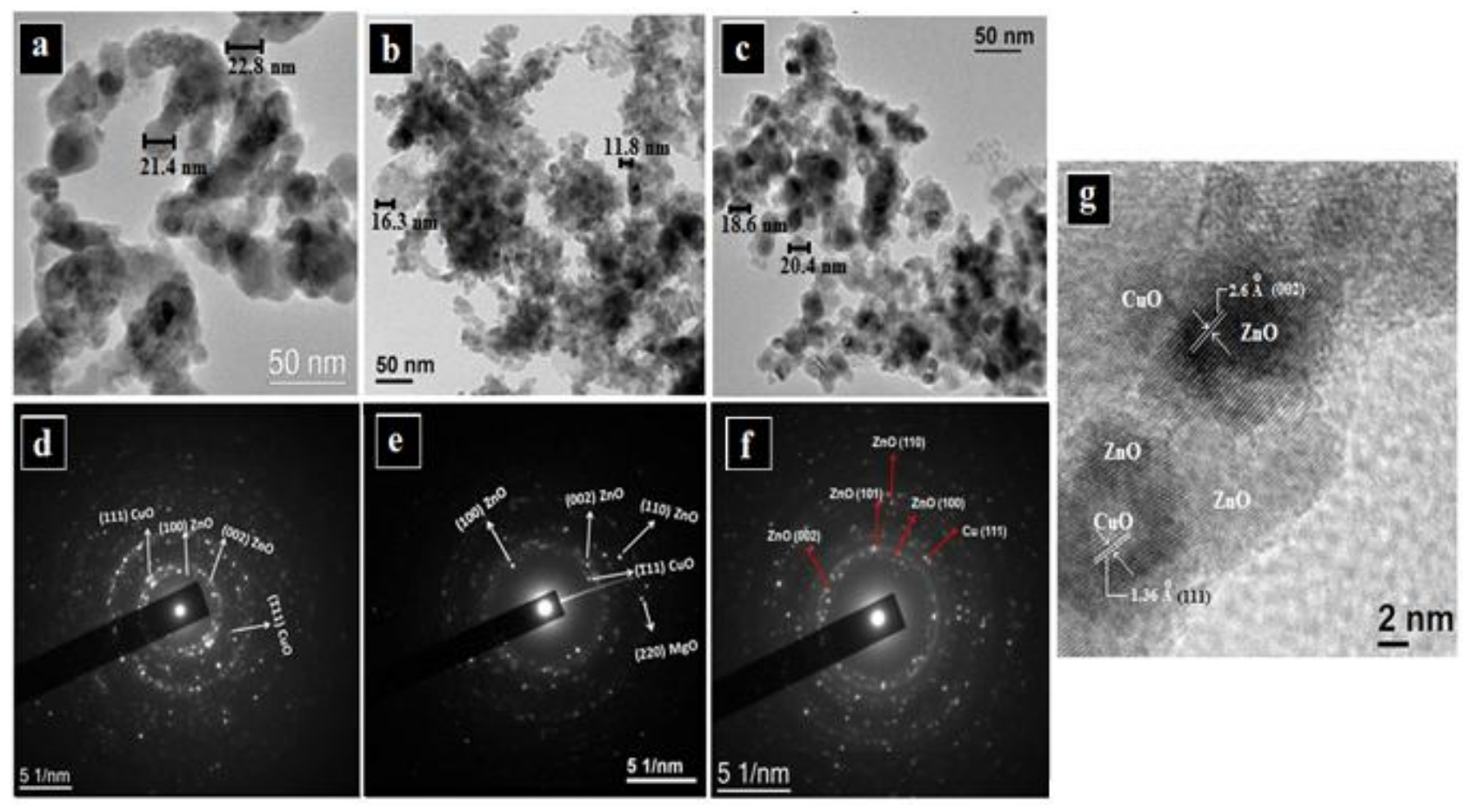

Figure 5. TEM images for calcined $\operatorname{CZM}(0)$ (a), $\operatorname{CZM(20)(b),~used~} \mathrm{CZM}(20)$ and (c). (d), (e), and (f) are SAED patterns for $\mathrm{CZM}(0), \operatorname{CZM}(20)$ and used $\mathrm{CZM}(20)$. Magnified TEM image of $\mathrm{CZM}(20)$ is shown in $(\mathrm{g})$.

\subsection{Specific Heat}

It is well known that syn-gas to DME conversion process is highly exothermic (equation 1), which may cause a thermal sintering of active catalytic sites and hence catalyst deactivation, if heat of the reaction is not dissipated properly. Such exothermal behavior can be controlled by adding high heat retention materials such as oxides of boron, beryllium, lithium and magnesium to the catalytic system [48]. This practice is used in well-known FCC (fluid catalytic cracking) reaction in which mixing of high heat capacity material with zeolite catalyst helps to control the reaction temperature as well as to increase the efficiency and product selectivity of the overall catalytic system. 
In the present work, we investigated the role of $\mathrm{MgO}$ in controlling the exothermicity of the reaction for which we theoretically calculated the specific heat capacity for all hybrid catalysts. This calculation was done by using the literature heat capacity values of each individual components of the catalyst system [49]. Considering the reduced state of the catalyst as $\mathrm{Cu}^{0}$, the calculated heat capacity values of the catalysts is plotted as a function of their $\mathrm{MgO}$ content (Figure 6). The plot shows an increase in specific heat capacity of the catalysts with an increase in $\mathrm{MgO}$ content. Thus, the temperature of the reaction is better controlled when more $\mathrm{MgO}$ is present in the catalyst, which makes the catalyst more stable towards thermal sintering and hence increases catalyst lifespan. Moreover, the ability to control the desired temperature of the reaction has beneficial effect in improving DME selectivity as DME is known to degrade to hydrocarbons at higher temperatures.

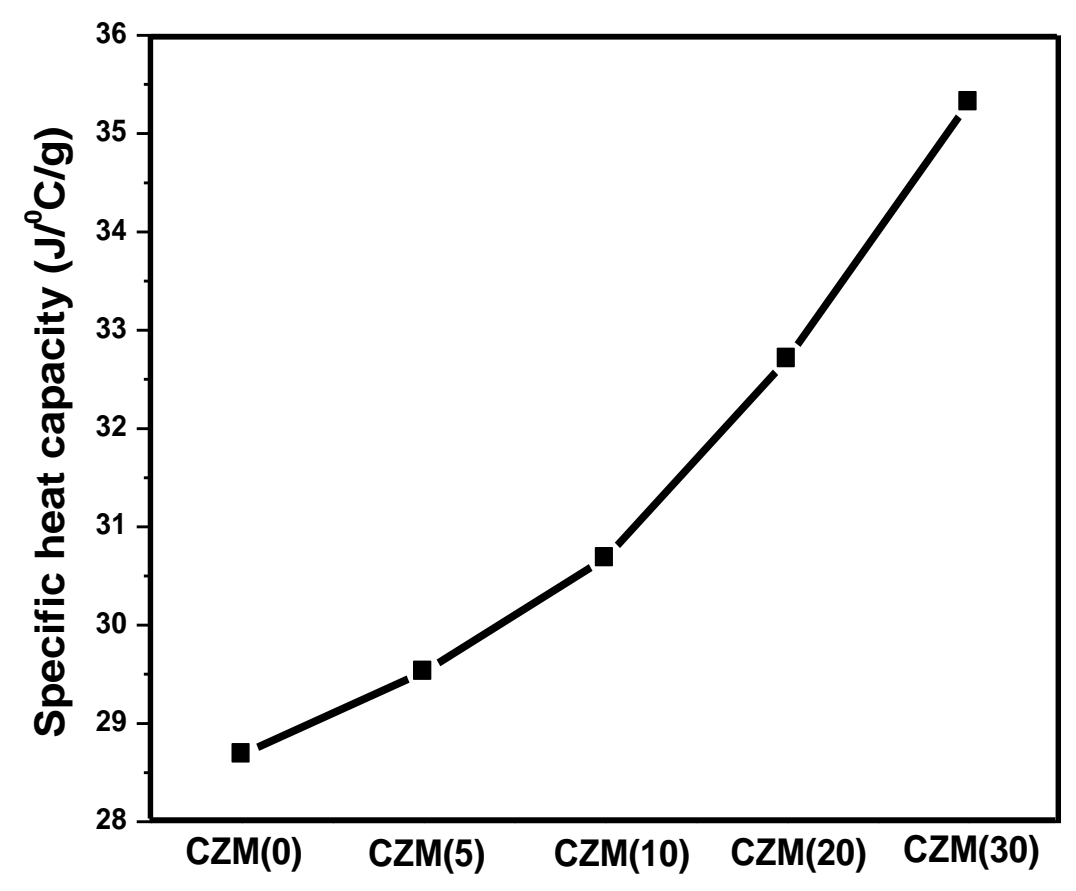

Figure 6. Calculated specific heat capacity of the reduced form of the hybrid catalysts as a function of $\mathrm{MgO}$ content in the catalysts composition.

\subsection{Catalytic Activity}

As discussed under experimental section, the effectiveness of the hybrid catalysts for the conversion of $\mathrm{CO}$ in $\mathrm{H}_{2}$ and $\mathrm{CO}$ gas feed $\left(\mathrm{H}_{2}: \mathrm{CO}=1.5\right)$ were tested on a fixed bed tubular reactor. Detailed experimental conditions and quantification of $\mathrm{CO}$ conversions and products and byproducts selectivity are discussed in the experimental section. The results of the catalysis experiments are summarized in Figure 7. Among all the hybrid catalysts containing $\mathrm{CZM}(0)-$ $\mathrm{CZM}(30)$ as MSC counterpart and $\gamma-\mathrm{Al}_{2} \mathrm{O}_{3}$ as $\mathrm{MDC}$, the catalyst containing $\mathrm{CZM}(0)$ show the lowest activity in terms of DME selectivity (36\%), CO conversion (19\%) and by-products 
selectivity ( $48 \%$ for $\mathrm{CO}_{2}$ and $8 \%$ for $\mathrm{C}_{1}$ and $\mathrm{C}_{2}$ hydrocarbons). Both $\mathrm{CO}$ conversions and DME selectivity improved from 28 to $37 \%$ and from 50 to $83 \%$, respectively, when $\mathrm{MgO}$ incorporation in the catalysts increased from 5 to $20 \mathrm{wt} \%$. The formation of $\mathrm{CO}_{2}$ and $\mathrm{C}_{1}-\mathrm{C}_{2}$ by-products were also decreased as $\mathrm{MgO}$ incorporation in the catalysts increased. Additionally, $\mathrm{MgO}$ incorporated catalysts completely dehydrated methanol that was formed as an intermediate, as methanol was not detected in the product. The catalyst containing $\mathrm{CZM}(20)(20 \mathrm{wt} \% \mathrm{MgO})$ as MSC counterpart showed maximum activity, enabling highest DME yield $(34 \%)$ and least by-product $\left(5 \% \mathrm{CO}_{2}\right)$. When compared the activity of the catalysts containing $\operatorname{CZM}(0)$ and $\operatorname{CZM}(20)$, the latter catalyst achieved about $27 \%$ higher DME yield than the former. However, the catalyst containing CZM(30) (30 mol\% $\mathrm{MgO}$ ) as MSC component showed lower activity, in terms of both CO conversion (20\%) and DME selectivity (70\%), when compared with the catalyst containing CZM(20). Mass balance for all hybrid catalyzed reactions was found out to be in the range of $96-100 \%$.

This observed trend in activity of the catalysts can be explained by the change of surface and physico-chemical properties of the catalysts with an increase in $\mathrm{MgO}$ content that might alter the reaction kinetics of the STD process. As discussed under catalysts characterization section, the higher activity of $\mathrm{MgO}$ containing catalysts, especially $\mathrm{CZM}(20)$, can directly be related to its optimum $\mathrm{Cu}: \mathrm{Zn}$ value of 70:30 (2.3). At this optimum $\mathrm{Cu}$ to $\mathrm{Zn}$ value, $\mathrm{MgO}$ believed to act as an efficient structural promoter, resulting in the formation of an active malachite precursor phase, which has reflected to its reduction profile. The lower activity of the $\mathrm{CZM}(5)$ and $\mathrm{CZM}(10)$ containing catalysts, possessing similar structure, can be explained by the formation of less uniformly dispersed $\mathrm{CuO}$ phase along with higher crystallite size particles upon calcination, whereas $\mathrm{CZM}(20)$ produced more uniformly dispersed porous $\mathrm{CuO}$ phase with lowest crystallite size, resulting in high surface area (Table 2). The lower activity of the catalyst without any $\mathrm{MgO}$ is presumably dominated by its aurichalcite structure which is considered to be less active for syn-gas to DME reaction. The decreased activity of the catalyst containing $\operatorname{CZM}(30)$ could be attributed to the presence of excess $\mathrm{MgO}$ in it and hence less $\mathrm{ZnO}-\mathrm{CuO}$ interaction, resulting in lower reduction activity as seen from TPR experimental data. 


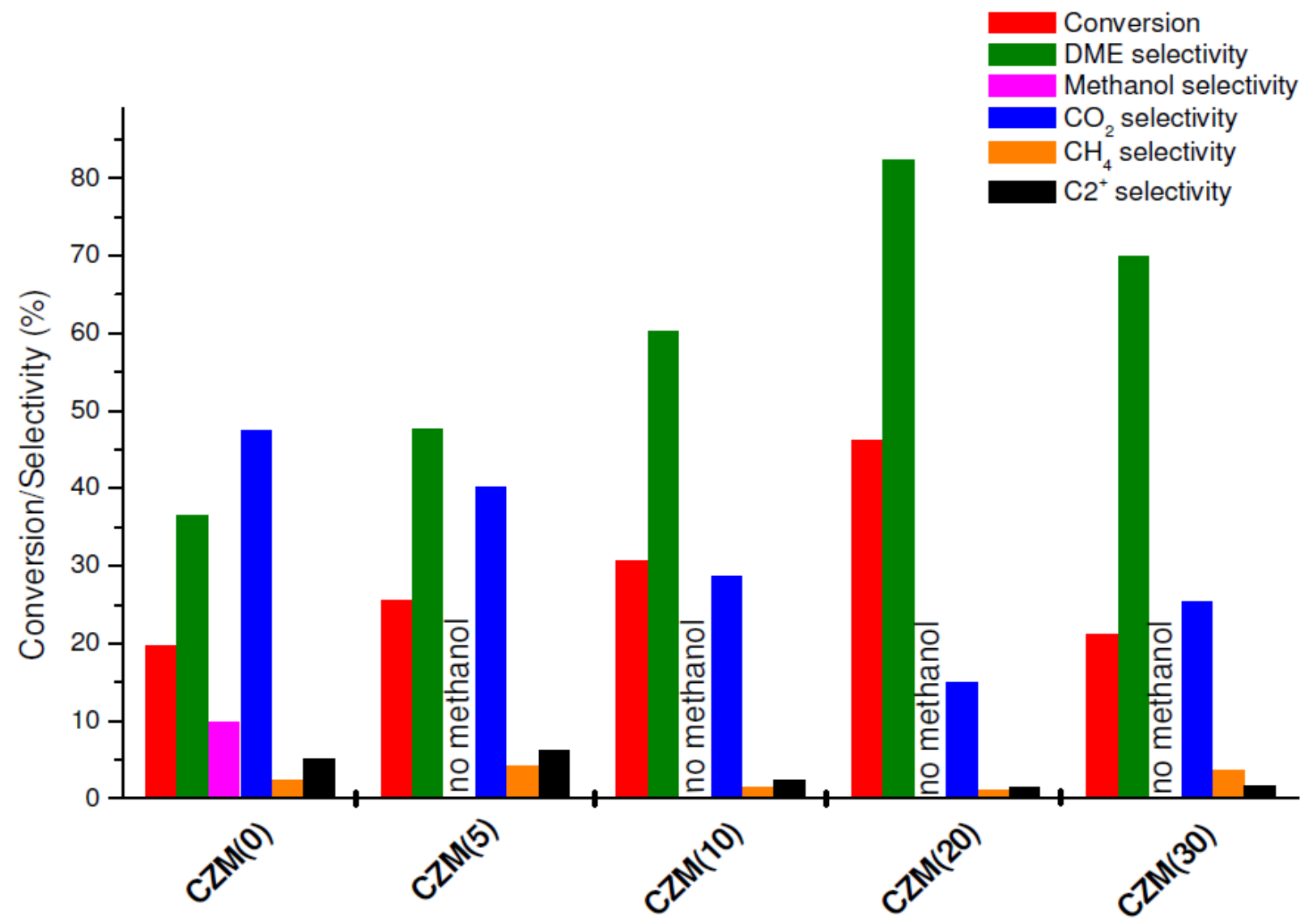

Figure 7. The hybrid $\left(\mathrm{CZM}-\gamma-\mathrm{Al}_{2} \mathrm{O}_{3}\right)$ catalyzed conversion of $\mathrm{CO}$ and selectivity of the products. Reaction conditions: 30 bar, $260^{\circ} \mathrm{C}, 20001 \mathrm{WHSV}$ and $\mathrm{H}_{2} / \mathrm{CO}$ ratio=1.5.

TOF values for all hybrid catalysts were calculated from the rates of $\mathrm{CO}$ consumption measured from experiments presented in Figure 7 and the number of active $\mathrm{Cu}$ catalytic sites which were measured using $\mathrm{H}_{2}$ chemisorption method [50]. These results are tabulated in Table 2 and also plotted as a function of $\mathrm{MgO}$ variation in the catalysts (Figure 8). The results show maximum TOF $\left(8.3 \times 10^{-2} \mathrm{~s}^{-1}\right)$ and $\mathrm{CO}$ conversion $(46 \%)$ for $\mathrm{CZM}(20)-\gamma-\mathrm{Al}_{2} \mathrm{O}_{3}$ catalyzed reaction which contained optimal amount of $\mathrm{MgO}(20 \%)$. When compared the activity of our investigated catalysts with a reported catalyst, $\mathrm{CuO} / \mathrm{ZnO} / \gamma-\mathrm{Al}_{2} \mathrm{O}_{3}$, showing TOFs in the range of $8-28 \times 10^{-2} \mathrm{~s}^{-1}$ for the conversion of syn-gas to DME, the activity of our $\mathrm{CZM}(20)-\gamma-\mathrm{Al}_{2} \mathrm{O}_{3}$ catalyst is comparable in the lower range with the reported TOF values [51]. In the reported system, TOF values were calculated based on $\mathrm{Cu}$ sites that were obtained from $\mathrm{N}_{2} \mathrm{O}$ titration method [52]. Additionally, the latter catalyst $\left(\mathrm{CZM}(20)-\gamma-\mathrm{Al}_{2} \mathrm{O}_{3}\right)$ produced DME with high selectivity than the reported one. 


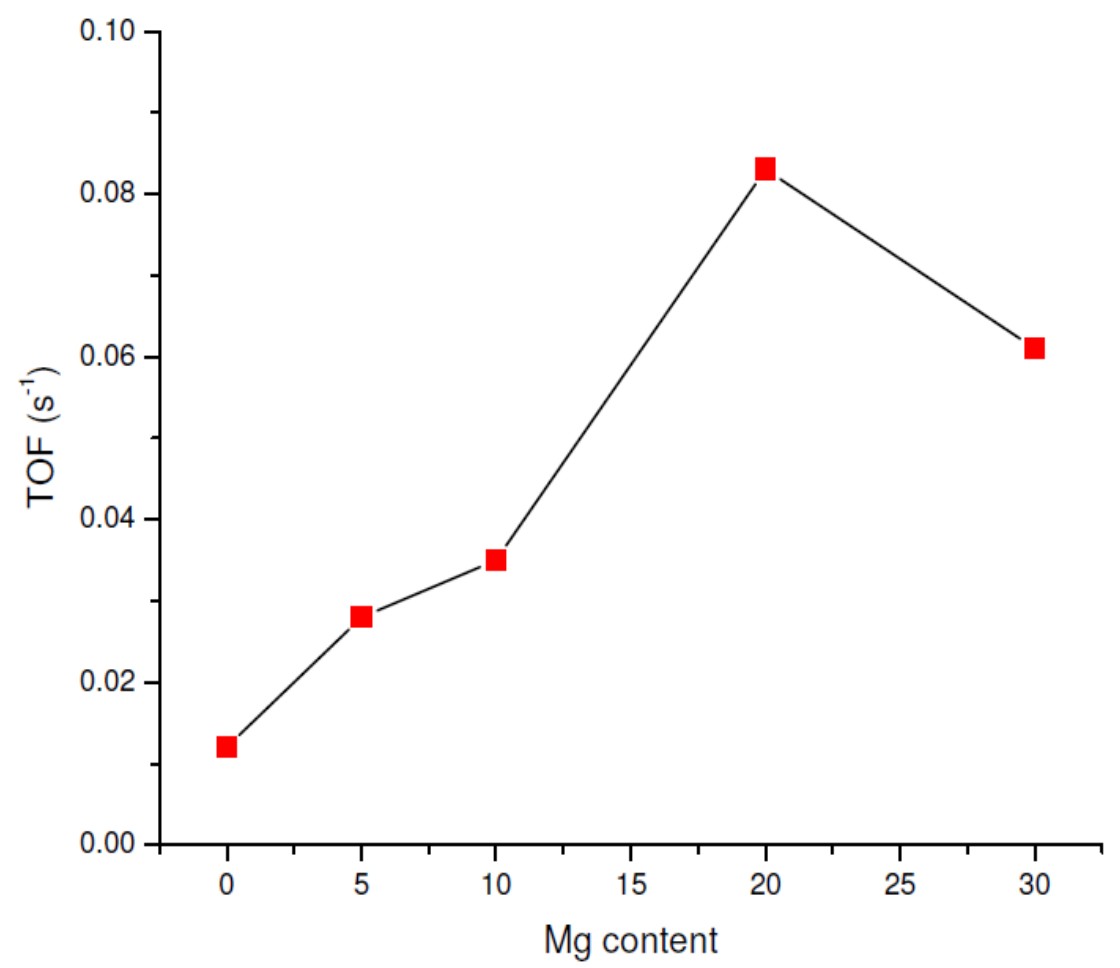

Figure 8. Correlation of TOF values (rate of $\mathrm{CO}$ conversion/active $\mathrm{Cu}$ atoms/s) with $\mathrm{MgO}$ content in the catalytic systems.

The observed activity of the hybrid catalysts can also be explained from the measured acidity and reducibility data. As discussed under $\mathrm{NH}_{3}$-TPD result, weak, medium and strong acid sites and the total acidity of the catalysts changed in the presence of different of amount of $\mathrm{MgO}$ promoter. It is evident from the literature that weak and medium acid sites facilitated DME formation, whereas strong acid sites accelerated DME degradation to by-products such as $\mathrm{CO}_{2}$ and hydrocarbons [29, 52-53]. In this context, the present results showing maximum DME yield and least by-products formation by the catalyst containing $20 \% \mathrm{MgO}$ also correlated well with its observed acidic properties of being the one which contained highest amount medium acid sites and least strong acid sites. These observations are also in accordance with the results obtained by Mao et al [32]. The authors reported the formation of high amount of by-products using catalysts that contained high amount of strong acid sites. However, CZM(30) catalyst, despite having less stronger acidic sites than $\mathrm{CZM}(20)$, showed lower selectivity in DME. This might be due to the more basic nature of $\mathrm{CZM}(30)$ as it contained highest amount of $\mathrm{MgO}$.

Furthermore, for methanol dehydration to DME, basic sites of the catalysts are required along with Lewis acidic $\gamma-\mathrm{Al}_{2} \mathrm{O}_{3}$. Mao et al. have also reported the importance of basic sites in the catalyst composition [32].

$$
\begin{aligned}
& \mathrm{CH}_{3} \mathrm{OH}+\mathrm{S}_{\mathrm{A}} \longleftrightarrow \mathrm{CH}_{3} \mathrm{OH} \cdot \mathrm{S}_{\mathrm{A}} \\
& \mathrm{CH}_{3} \mathrm{OH}+\mathrm{S}_{\mathrm{B}} \longleftrightarrow \mathrm{CH}_{3} \mathrm{OH} \cdot \mathrm{S}_{\mathrm{B}}
\end{aligned}
$$




$$
\begin{aligned}
& \mathrm{CH}_{3} \mathrm{OH} \cdot \mathrm{S}_{\mathrm{B}}+\mathrm{S}_{\mathrm{B}} \leftarrow \mathrm{CH}_{3} \mathrm{O}^{-} \cdot \mathrm{S}_{\mathrm{B}}+\mathrm{H}^{+} \cdot \mathrm{S}_{\mathrm{B}} \\
& \mathrm{CH}_{3} \mathrm{OH} \cdot \mathrm{S}_{\mathrm{A}}+\mathrm{CH}_{3} \mathrm{O}^{-} \cdot \mathrm{S}_{\mathrm{B}} \leftarrow \rightarrow \mathrm{CH}_{3} \mathrm{OCH}_{3} \cdot \mathrm{S}_{\mathrm{B}}+\mathrm{OH}^{-} \cdot \mathrm{S}_{\mathrm{A}} \\
& \mathrm{H}^{+} \cdot \mathrm{S}_{\mathrm{B}}+\mathrm{OH}^{-} \cdot \mathrm{S}_{\mathrm{A}} \leftarrow \mathrm{H}_{2} \mathrm{O} \cdot \mathrm{S}_{\mathrm{B}}+\mathrm{S}_{\mathrm{A}} \\
& \mathrm{CH}_{3} \mathrm{OCH} \cdot \mathrm{S}_{\mathrm{B}} \leftarrow \longrightarrow \mathrm{CH}_{3} \mathrm{OCH}_{3}+\mathrm{S}_{\mathrm{B}} \\
& \mathrm{H}_{2} \mathrm{O} \cdot \mathrm{S}_{\mathrm{B}} \longrightarrow \rightarrow \mathrm{H}_{2} \mathrm{O}+\mathrm{S}_{\mathrm{B}} \\
& 2 \mathrm{CH}_{3} \mathrm{OH} \leftarrow \longrightarrow \mathrm{CH}_{3} \mathrm{OCH}_{3}+\mathrm{H}_{2} \mathrm{O}
\end{aligned}
$$

$\mathrm{S}_{\mathrm{A}}$ and $\mathrm{S}_{\mathrm{B}}$ correspond to acid and base sites. According to the mechanism, bimolecular reaction of methanol conversion involved a weakly adsorbed $\mathrm{CH}_{3} \mathrm{OH}$ on a basic site $\left(\mathrm{S}_{\mathrm{B}}\right)$ through hydrogen bonding and a strongly adsorbed $\mathrm{CH}_{3} \mathrm{OH}$ on an acidic site $\left(\mathrm{S}_{\mathrm{A}}\right)$ through a coordination bond. While $\mathrm{CH}_{3} \mathrm{OH}$ on the acidic site can polarize the $\mathrm{C}-\mathrm{O}$ bond to make hydroxyl a better leaving group, the weakly adsorbed $\mathrm{CH}_{3} \mathrm{OH}$ on the basic site enhances the nucleophilicity of oxygen such that this $\mathrm{CH}_{3} \mathrm{OH}$ can be considered as an incipient alkoxide ion (eq 4), which can influence a nucleophilic displacement of a positively polarized carbon atom of the alcohol adsorbed to the acidic site to form DME (eq 5) [54-55].

Assuming our STD process follows the similar methanol dehydration mechanism, $\mathrm{MgO}$ is believed to serve the basic sites to progress the reaction. Therefore the mechanism adapted here can reasonably explain our experimental results elucidating the positive effect of $\mathrm{MgO}$ in $\mathrm{CZM}(20)$ by providing the reasonable basic nature to the catalyst system which resulted in increased DME selectivity and decreased the byproducts selectivity.

It is noted from the catalysis results that among all the catalysts containing the same amount of $\gamma-\mathrm{Al}_{2} \mathrm{O}_{3}$, only $\mathrm{CZM}(0)$ catalyzed reaction showed unconverted methanol in the product (Figure 7). As methanol was completely converted in the presence of $\mathrm{MgO}$, the role of $\mathrm{MgO}$ in enhancing the dehydration activity of $\gamma-\mathrm{Al}_{2} \mathrm{O}_{3}$ is evident. To further analyze the role of $\mathrm{MgO}$ in reaction kinetics, we considered the following reaction scheme for the conversion of syn-gas to DME.

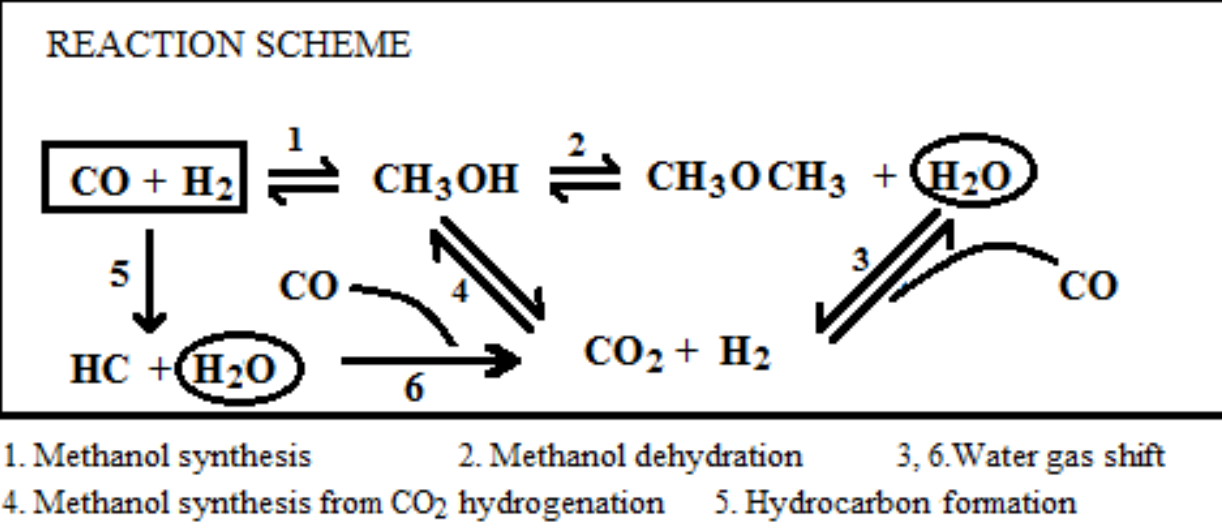

Scheme 1. Proposed reaction scheme for the conversion of syn-gas to DME. 
Based upon the catalytic results obtained, we can propose that reactions 1 and 2 of Scheme 1 are favored by the presence of $\mathrm{MgO}$, and hence the formation of by-products via reactions 3,4 and 5 are minimized. There are two competitive pathways for $\mathrm{CO}_{2}$ formation, one via water gas shift (WGSR) and other via methanol degradation. It is believed that faster methanol dehydration in the presence of $\mathrm{MgO}$ slowed down $\mathrm{CO}_{2}$ formation via methanol degradation. Additionally, favored hydrogenation of $\mathrm{CO}_{2}$, formed from WGSR [56], by the $\mathrm{Cu} / \mathrm{ZnO} / \mathrm{MgO} / \gamma-\mathrm{Al}_{2} \mathrm{O}_{3}$ catalyst $[35,57-58$ ] reverses the equilibrium of reaction 4 towards methanol side, which results in the formation of more methanol intermediate and hence higher selectivity in DME via methanol dehydration and less selectivity in $\mathrm{CO}_{2}$. It is also possible that the WGSR was suppressed by the investigated catalysts.

Mass transport calculation was carried out for the best catalyst, which in the present study is $\mathrm{CZM}(20)-\gamma-\mathrm{Al}_{2} \mathrm{O}_{3}$ (see supplementary information). The Mears criterion [59]

$$
\frac{-r_{A}^{\prime} \rho_{b} R n}{k_{c} C_{A b}}<0.15
$$

gave $2.34 \times 10^{-6}<0.15$ indicating no diffusion limitations. As far as heat transfer limitation is concerned, our catalytic system totally complies with the criterion because during the reaction, the temperature difference between the internal catalyst bed and the external wall of the reactor was less than $2^{0} \mathrm{C}$ suggesting the capability of the catalyst to qualify for the heat transfer criterion as well.

Effect of reaction temperature and pressure. In order to determine the influence of different reaction parameters such as reaction temperature, pressure, space velocity and $\mathrm{H}_{2} / \mathrm{CO}$ ratio, $\mathrm{CZM}(20)-\gamma-\mathrm{Al}_{2} \mathrm{O}_{3}$ was chosen as a model catalyst because of its optimal activity in $\mathrm{CO}$ conversion and DME yield. For a better interpretation and evaluation of results, equilibrium $\mathrm{CO}$ conversions and DME selectivity were calculated by using Aspen Plus ${ }^{\circledR}$ model (V7.1, Aspen Technology Inc.). The calculated values along with experimental results for temperature and pressure variations are shown in Figure 9. Under experimental conditions of $\mathrm{H}_{2} / \mathrm{CO}$ ratio of 1.5 and space velocity of $2000 \mathrm{ml} / \mathrm{g}_{\text {cat }} \cdot \mathrm{h}$, the results show an increase in CO conversions as the reaction temperatures and pressures increased from 240 to $280{ }^{\circ} \mathrm{C}$ and 30 to 50 bar (Figure 9a), although this increase is more predominant under experimental conditions. From the trend of change, it is reasonable to predict that the experimental conversions could be equivalent to that of equilibrium values at higher temperatures, although this 

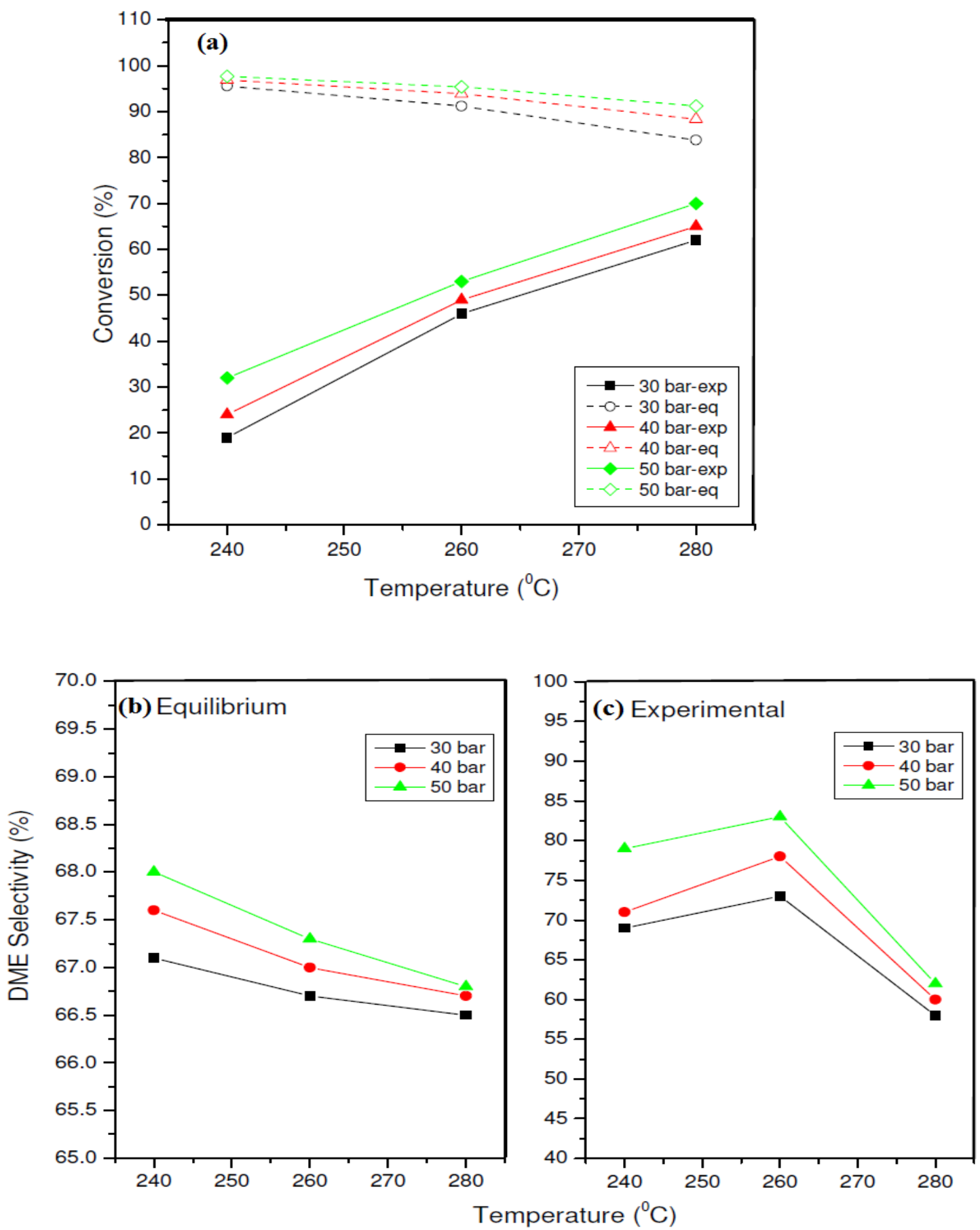

Figure 9. Temperature and pressure dependence on $\mathrm{CZM}(20)-\gamma-\mathrm{Al}_{2} \mathrm{O}_{3}$ catalyzed $\mathrm{CO}$ conversions (a) and DME selectivity (b,c), where eq= equilibrium (dashed lines) and exp= experimental (solid lines). Reaction conditions: $\mathrm{H}_{2} / \mathrm{CO}$ ratio $=1.5$, Space velocity $=2000 \mathrm{ml} / \mathrm{g}_{\text {cat }} \cdot \mathrm{h}$.

study was not performed at above $280{ }^{\circ} \mathrm{C}$ to prevent an irreversible deactivation of MSC component of the catalyst, owing to sintering effects of copper particles. Furthermore, CO conversions at higher temperatures could be limited by thermodynamic equilibrium conversion [41]. In case of DME selectivity, the results show that the experimental DME selectivity at high pressures (>40 bar) are higher than those of equilibrium values. When compared as a function of temperature raise, the 
experimental selectivity values were found to increase from 240 to $260{ }^{\circ} \mathrm{C}$ and then decreased at $280{ }^{\circ} \mathrm{C}$ (Figure 9c).

Influence of $\mathrm{H}_{2} / \mathrm{CO}$ ratio. The effect of $\mathrm{H}_{2} / \mathrm{CO}$ ratios on the conversions of $\mathrm{CO}$ was studied by varying $\mathrm{H}_{2} / \mathrm{CO}$ ratio in the range of $1-3$ at fixed temperature $\left(260{ }^{\circ} \mathrm{C}\right)$, pressure $(30 \mathrm{bar})$ and space velocity (2000 ml/g $\mathrm{g}_{\text {cat }}$ h). The results (Figure 10a) show about $20 \%$ increase in CO conversions with an increase in $\mathrm{H}_{2} / \mathrm{CO}$ ratio from 1 to 3 . The yields of by-products $\left(\mathrm{CO}_{2}, \mathrm{C}_{1}-\mathrm{C}_{4}\right.$ hydrocarbons) were also increased with an increase in $\mathrm{H}_{2} / \mathrm{CO}$ ratios, resulting in a decrease in DME selectivity. As discussed Scheme 1, higher $\mathrm{CO}_{2}$ by-product formation at higher $\mathrm{H}_{2} / \mathrm{CO}$ value may be associated with enhanced WGSR activity (scheme 1 , reaction $3 \& 6$ ) by water formed from reactions 2 and 5 (Scheme 1), owing to higher CO conversions and higher C1-C2 hydrocarbons formation.
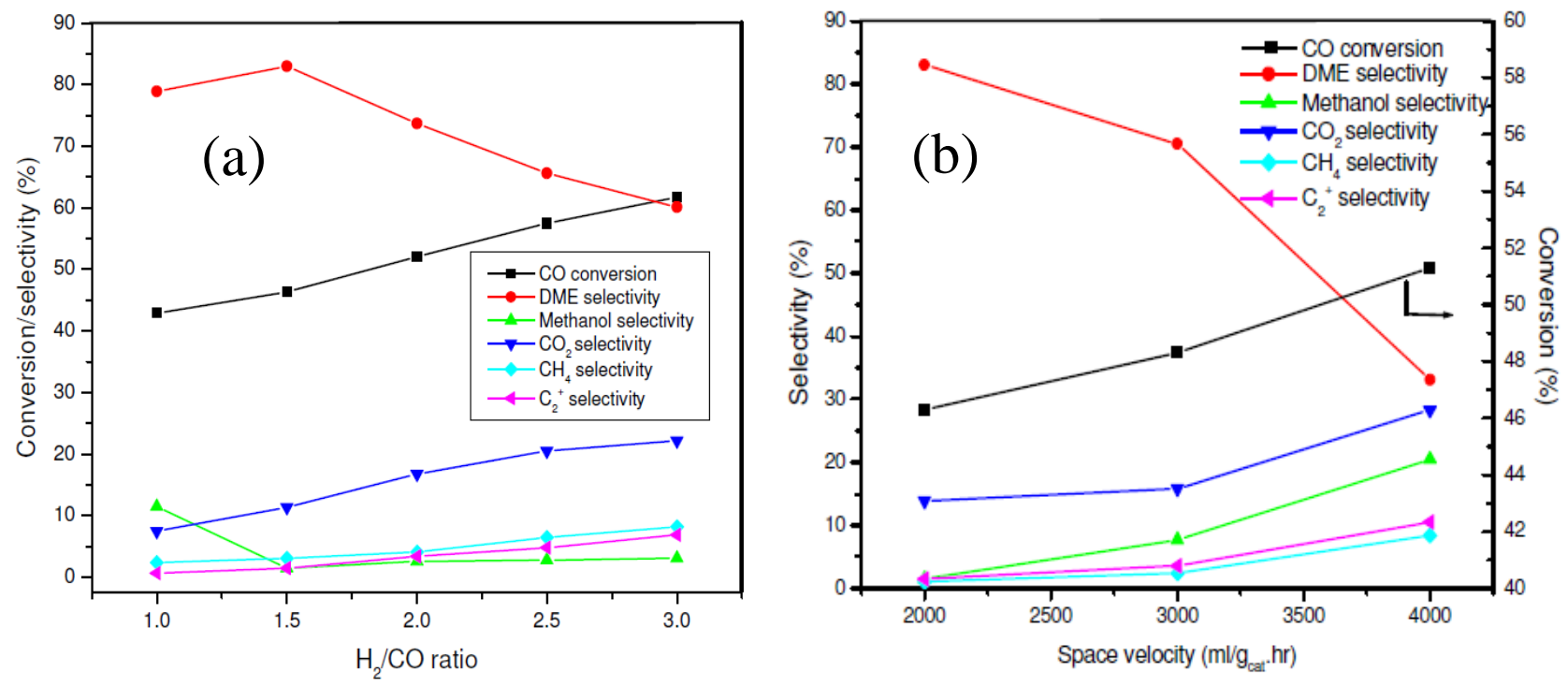

Figure 10. The effect of (a) $\mathrm{H}_{2} / \mathrm{CO}$ ratio and (b) space velocity on $\mathrm{CZM}(20)-\gamma-\mathrm{Al}_{2} \mathrm{O}_{3}$ catalyzed CO conversions and products selectivity. Reaction conditions: $\mathrm{T}=260{ }^{\circ} \mathrm{C}$, pressure $=30 \mathrm{bar}$ and $\mathrm{H}_{2} / \mathrm{CO}$ ratio $=1.5$.

Influence of space velocity. The influence of space velocity on $\mathrm{CO}$ conversions was studied by varying space velocity in the range of $2000-4000 \mathrm{ml} / \mathrm{g}_{\text {cat }} \cdot \mathrm{h}$ at fixed $\mathrm{H}_{2} / \mathrm{CO}$ ratio of 1.5 in the feed gas. As shown in Figure 10b, an increase in space velocity from 2000 to $4000 \mathrm{ml} / \mathrm{g}_{\text {cat }} \cdot \mathrm{h}$ caused a significant increase in by-products formation as well as decrease in methanol dehydration, resulting in a drop of DME selectivity by as much as $60 \%$ and an increase in unconverted methanol in the product. The effect is more pronounced in the range of space velocity of $3000-4000 \mathrm{ml} / \mathrm{g}_{\text {cat }} \cdot \mathrm{h}$. However, CO conversions varied a little (about 10\%) in the entire range of space velocity. The observed results at higher space velocity could attribute to the higher rate of methanol formation 
than its dehydration, resulting in methanol accumulation in the product stream. Consequently, reverse equilibrium of reaction 1 (Scheme 1) could favor $\mathrm{CO}$ conversion via reaction 5 , and hence the formation of more $\mathrm{C} 1-\mathrm{C} 2$ hydrocarbons and $\mathrm{CO}_{2}$ via reactions 5 and 6 of Scheme 1 occurred. A similar trend was also noted in a previous report in which the authors reported almost constant conversion of CO and lower DME selectivity when the space velocity was increased by 3 folds [60]. This trend of CO conversion and DME selectivity as a function of space velocity has also been demonstrated in other literature reports [61-62].

\section{CONCLUSIONS}

The synthesis of five hybrid bifunctional catalysts consisting of $\mathrm{CZM}$ materials $(\mathrm{C}=\mathrm{Cu}, \mathrm{Z}=$ $\mathrm{Zn}, \mathrm{M}=\mathrm{Mg}$ ) of varying amount of $\mathrm{MgO}$ as a promoter and their characterizations by XRD, SEM, TEM, $\mathrm{NH}_{3}$-TPD and $\mathrm{H}_{2}$-TPR methods are reported. The characterization data suggests that the surface properties, pore diameter, morphology and crystallinity, the nature of acidic sites and reducibility of the catalysts depend on the amount $\mathrm{MgO}$ presence. It is observed that $\mathrm{MgO}$ (up to $20 \%$ ) enhances the formation of crystalline malachite structure as an active catalyst precursor for syn-gas to DME (STD) conversion process. Non-crystalline material with high degree of amorphous nature is formed when $30 \% \mathrm{MgO}$ was added during CZM material synthesis. Assynthesized CZM materials act as methanol synthesis catalysts (MSC), which were homogeneously mixed with $\gamma-\mathrm{Al}_{2} \mathrm{O}_{3}$ as methanol dehydration catalyst (MDC) in 2:1 weight ratio to prepare hybrid catalysts. The catalytic effectiveness of the hybrid bifunctional catalysts has been tested for direct conversions of syn-gas (a mixture of $\mathrm{H}_{2}$ and $\mathrm{CO}$ gas of ratio 1.5) on a fixed bed tubular reactor. $\mathrm{CO}$ conversions, DME and by-products $\left(\mathrm{CO}_{2}, \mathrm{C}_{1}-\mathrm{C}_{2}\right.$ hydrocarbons) selectivity were determined to measure the effectiveness of the hybrid catalysts. The results show maximum effectiveness of the catalyst containing $20 \% \mathrm{MgO}$, in terms of high CO conversion (37\%), high DME selectivity (83\%) and low by-products selectivity (14\%). It is explained that uniformly dispersed and accessible malachite crystallite structure of catalyst precursor, medium acidic sites, low pore diameter, optimum $\mathrm{Cu}$ to $\mathrm{Zn}$ ratio of 2.3 and favored heat capacity in controlling heat rise of the exothermic reaction are the reasons for higher activity of the catalyst containing $20 \% \mathrm{MgO} . \mathrm{CZM}(20)-\gamma-\mathrm{Al}_{2} \mathrm{O}_{3}$ was used as a model catalyst for studying $\mathrm{CO}$ conversions in syn-gas as a function of reaction temperature, pressure, space velocity and $\mathrm{H}_{2} / \mathrm{CO}$ ratio. The results show a significant variation of products distribution in the eluent due to variation of reaction parameters. Higher temperature $\left(>260{ }^{\circ} \mathrm{C}\right), \mathrm{H} 2 / \mathrm{CO}$ ratio $(>1.5)$ and space velocity $\left(>2000 \mathrm{ml} / \mathrm{g}_{\mathrm{cat}} \cdot \mathrm{h}\right)$ resulted in the formation of more by-products and hence decreased DME selectivity. 


\section{ACKNOWLEDGEMENTS}

SA is grateful to Petrotech Society of India for a Petrotech Research Fellowship. BS and RKV acknowledge Petrotech Society of India for providing financial support for a collaboration research project between Bharat Petroleum Corporation Ltd. (BPCL) and University of Delhi. SA, RKV and CS acknowledge higher management of BPCL, Corporate research and development center for providing the infrastructure to carry out the research work. AB and BS thank DST, New Delhi for funding through DST-SERB project grant for conducting this research as part at the University of Delhi. BS also acknowledges the financial support from the Catalysis Center for Energy Innovation, an Energy Frontier Research Center funded by the U.S. Department of Energy, Office of Science, Office of Basic Energy Sciences under Award number DE-SC0001004 for the later stages of this manuscript. The authors acknowledge Mr. Pranab K. Rakshit (Bharat Petroleum Corp. Ltd.) and Mr. Pintu Maity (Bharat Petroleum Corp. Ltd.) for helpful technical discussions.

\section{REFERENCES}

[1] S. H. Lima, A. M. S. Forrester, L. A. Palacio, A. C. Faro Jr., App. Catal. A: Gen. 488 (2014) 19.

[2] X. L. Meng, R. Z. Chu, B. Qin, E. W. Yue, T. T. Chen, X. Ywei, Energy sourc. A: Recovery util. environ. effects 37 (2015) 870.

[3] DME Handbook, Japan DME Forum, 2007.

[4] S. W. Kang, J. W. Bae, K.W. Jun, H. S. Potdar, Catal. Commun. 9 (2008) 2035.

[5] C. Arcoumanis, C. Bae, R. Crookes, E. Kinoshita, Fuel 87 (2008) 1014.

[6] M. R. Rahimpour, A. K. Mostafazadeh, M. M. Barmaki, Fuel Process. Technol. 89 (2008) 1396.

[7] M. Farniaei, M. Abbasi, A. Rasoolzadeh, M. R. Rahimpour, J. Nat. Gas Chem. 14 (2013) 158.

[8] R. Phienluphon, K. Pinkaew, G. Yang, J. Lie, Q. Wei, Y. Yoneyama, T. Vitidsant, N. Tsubaki, Chem. Eng. J. 270 (2015) 605.

[9] K. G. Mbuyi, M. S. Scurrell, D. Hildebrandt, D. Glasse, Top. Catal. 55 (2012) 771.

[10] Y. Wang, W. Wang, Y. Chen, J. Ma, R. Li, Chem. Eng. J. 250 (2014) 248.

[11] J. H. Kim, M. J. Park, S. J. Kim, O.S. Joo, K. D. Jung, Appl. Catal. A: Gen. 264 (2004) 37.

[12] M. Behrens, J.Catal. 267 (2009) 24.

[13] F. Arena, K. Barbera, G. Italiano, G. Bonura, L. Spadaro, F. Frusteri, J. Catal. 249 (2007) 185.

[14] D. Wallet, D. Stirling, F. S. Stone, F. S. Spencer, Faraday Discuss. 87 (1989) 107.

[15] I. Kasatkin, P. Kurr, B. Kniep, A. Trunschke, R. Schlögl, Angew. Chem. Int. Ed. 46 (2007) 7324. 
[16] M. Behrens, F. Studt, I. Kasatkin, S. Kühl, M. Hävecker, F. Abild-Pedersen, S. Zander, F. Girgsdies, P. Kurr, B. L. Kniep, M. Tovar, R.W. Fischer, J. K. Nørskov, R. Schlögl, Science 336 (2012) 893.

[17] J. C. Frost, Nature 334 (1988) 577.

[18] N. Y. Topsoe, H. Topsoe, Top. Catal. 8 (1999) 267.

[19] J. D. Grunwaldt, A. M. Molenbroek, N. Y. Topsoe, H. Topsoe, B.S. Clausen, J. Catal. 194 (2000) 452.

[20] T. Ressler, B. L. Kniep, I. Kasatkin, R. Schlögl, Angew. Chem. Int. Ed. 44 (2005) 4704.

[21] S. Zander, PhD dissertation, the Technical University of Berlin, 2013.

[22] M. Behrens, F. Z. Girgsdies, Anorg. Allg. Chem. 636 (2010) 919.

[23] M. V. Twigg, M. S. Spencer, Top. Catal. 22 (2003) 191.

[24] M. Kurtz, N. Bauer, C. Buscher, H. Wilmer, O. Hinrichsen, R. Becker, S. Rabe, K. Merz, M. Driess, R.A. Fischer, M. Muhler, Catal. Lett. 92 (2004) 49.

[25] R.Yang, Y. Zhang, Y. Iwama and N. Tsubaki, Appl.Catal. A: Gen. 288 (2005) 126.

[26] B. Hu, K. Fujimoto, Appl. Catal. B: Environ. 95 (2010) 208.

[27] T. Fitzpatrick, T. Hicks, Advances in methanol synthesis, March 2010.

[28] F. Yaripour, F. Baghaei, I. Schmidt, J. Perregaard, Catal. Commun. 6 (2005) 542.

[29] J. Wang, P. A. Chernavskii, A. Y. Khodakov, Y. Wang, J. Catal. 286 (2012) 51.

[30] Y. Fu, T. Hong, J. Chen, A. Auroux, J. Shen, Thermochim. Acta 434 (2005) 22.

[31] S. Jiang, Y. K. Hwang, S. H. Jhung, J. S. Chang, J.S. Hwang, T. X. Cai, Chem. Lett. 33 (2004) 148.

[32] D. Mao, W. Yang, J. Xia, B. Zhang, Q. Song, Q. Chen, J. Catal. 230 (2005) 140.

[33] P. P. Morajkar, J. B. Fernandes, Catal. Commun. 11 (2010) 414.

[34] (a) F. Yaripour, F. Baghaei, I. Schmidt, J. Perregaard, Catal. Commun. 6 (2005) 147; (b) S. Dutta, S. De, A. K. Patra, M. Sasidharan, A. Bhaumik, B. Saha, Appl. Catal. A: Gen. 409-410 (2011) 133; (c) S. K. Das, M. K. Bhunia, A. Bhaumik, Dalton Trans. 39 (2010) 4382.

[35] J. C. J. Bart, R. P. A Sneeden, Catal. Today 2 (1987) 1.

[36] B. Bems, M. Schur, A. Dassenoy, H. Junkes, D. Herein, R. Schlögl, Chem. Eur. J. 9 (2003) 2039.

[37] K. Klier, Adv. Catal. 31 (1982) 243.

[38] I. M. Cabrera, M. L. Granados, J. L. G. Fierro, Catal. Lett. 84 (2002) 153.

[39] R. G. Herman, K. Klier, G. W. Simmons, B. P. Finn, J. B. Bulko, T. P. Kobylinski, J. Catal. 56 (1979) 437. [40] P. B. Rasmussen, M. Kazuta, Y. Chorkendorff, Surf. Sci. 318 (1994) 267.

[41] M. Stiefel, R. Ahmad, U. Almond and M. Doring, Fuel Process.Technol. 92 (2011) 1466.

[42] J. W. Bae, S. H. Kang, K. W. Jun, Y. J. Lee, Ind. Eng. Chem. 15 (2009) 566. 
[43] J. W. Bae, S. H. Kang, K. W. Jun, Y. J. Lee, Appl. Catal. B: Environ. 90 (2009) 426.

[44] B. Lindström, L. J. Pettersson, P. G. Menon, Appl. Catal. A: Gen. 234 (2002) 111.

[45] S. H. Kang, J. W. Bae, S. H. Kim, G. M. Dhar, K. W. Jun, Energy Fuels 24 (2010) 804.

[46] J. Agrell, H. Birgersson, M. Boutonnet, I. M. Cabrera, R. Navarro, J. Fierro, J. Catal. 219 (2003) 389.

[47] X. M. Liu, G. Q. Lu, Z. F. Yan, Appl. Catal. A: Gen. 279 (2005) 241.

[48] C. M. T. Hayward, B. K. Speronello, W. R Gustafson, G. S. Koermer, European Patent 0224992 (1986).

[49] W. M. Haynes, CRC Handbook of Chemistry and Physics, $91^{\text {st }}$ edition, CRC press, Taylor \& Francis group, 2010-2011.

[50] M. B. Fichtl, J. Schumann, I. Kasatkin, N. Jacobsen, M. Behrens, R.Schlçgl, M. Muhler, O. Hinrichsen, Angew. Chem. Int. Ed. 53 (2014) 7043-7047.

[51] J. W. Jung, Y. J. Lee, S. H. Um, P. J. Yoo, D. H. Lee, K. W. Jun, J. W. Bae, Appl. Catal. B: Environ. 126 (2012) 1-8.

[52] K. W. Jun, M. H. Jung, K. S. R. Rao, M. J. Choi, K. W. Lee, Stud. Surf. Sci. Catal. 114 (1998) 447.

[53] R. Montesano, A. Narvaez, D. Chadwick, Appl.Catal. A: Gen. 482 (2014) 69.

[54] K. Kochloeft, W. Meye, J. Catal. 28 (1973), 69.

[55] H. Knözinger, D. Dautzenberg, J. Catal. 33 (1974) 142.

[56] T. Shishido, M. Yamamoto, I. Atake, D. Li, Y. Tian, H. Morioka, M. Honda, T. Sano, K. J. Takehira, Mol. Catal. A: Chem. 253 (2006) 270.

[57] K. M. V. Bussche, G.F. Froment, J. Catal 161 (1996) 1.

[58] B. Denise, R. P. A. Sneeden, Appl. Catal. 28 (1986) 235.

[59] S. T. Oyama, X. Zhang, J. Lu, Y. Gu, T. Fujitani, J. Catal. 257 (2008) 1-4.

[60] Z. Chen, H. Zhang, W. yang, D. Fang, World Acad Sci Eng Technol. 68 (2010).

[61] S. Allahyari, M. Haghighi, A. Ebadi, Chem. Eng. J. 262 (2015) 1175-1186.

[62] D. Mao, J. Xia, B. Zhang, G. Lu, Energy Convers. Manage. 51 (2010) 1134-1139. 


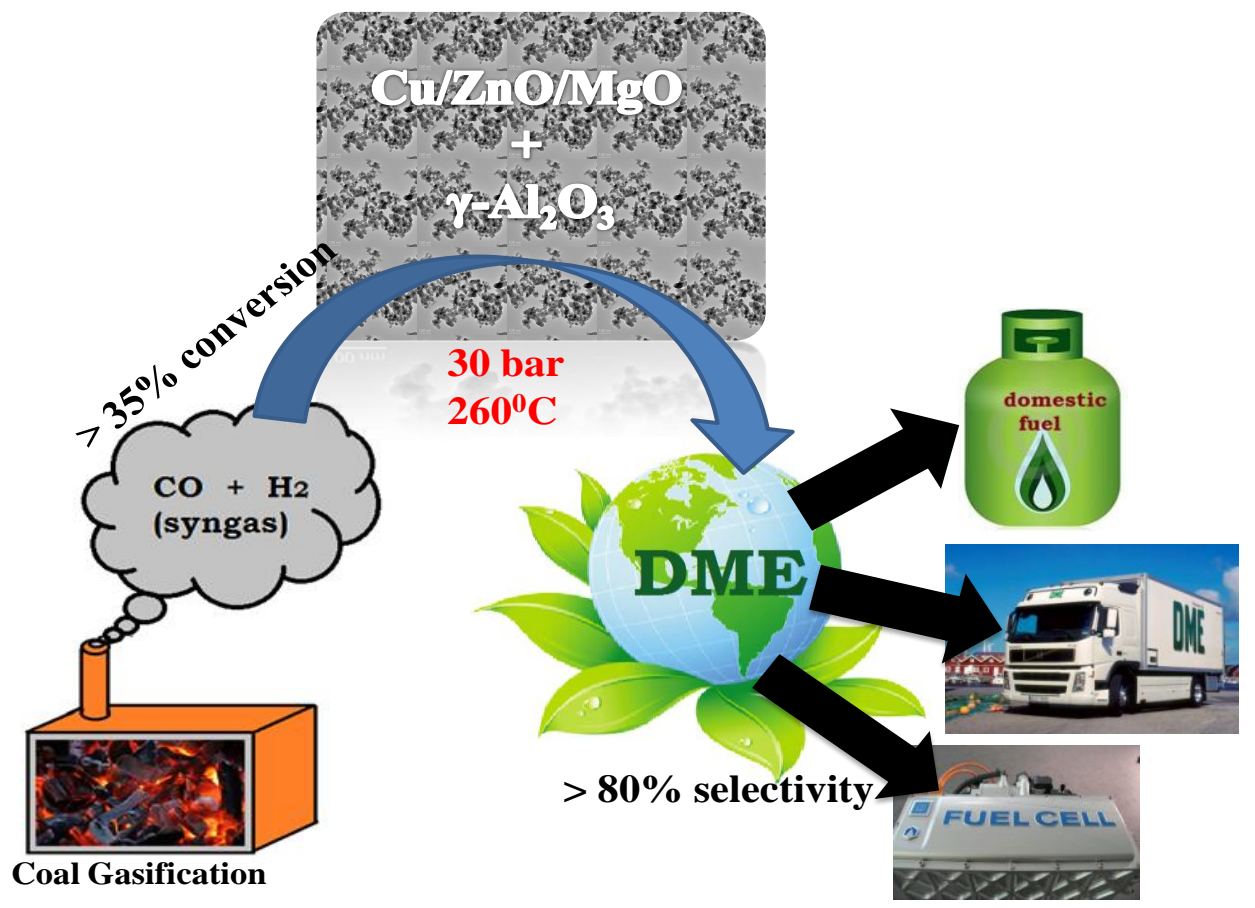

